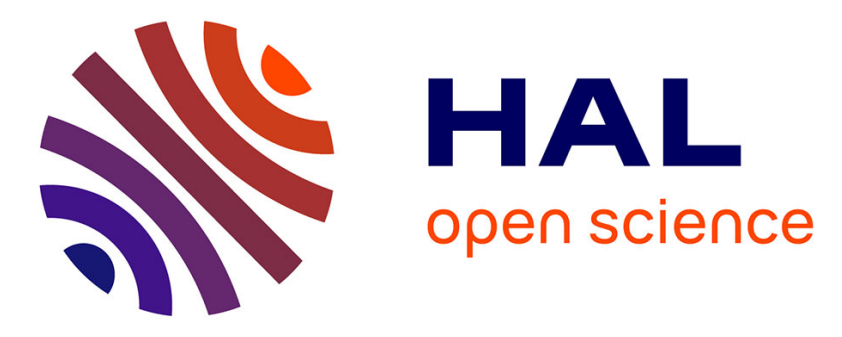

\title{
Correlation of chemical composition and odor concentration for emissions from pig slaughterhouse sludge composting and storage
}

Vincent Blazy, Amaury De-Guardia, Jean Claude Benoist, Mylène Daumoin, Fabrice Guiziou, Marguerite Lemasle, Dominique Wolbert, Suzelle Barrington

\section{To cite this version:}

Vincent Blazy, Amaury De-Guardia, Jean Claude Benoist, Mylène Daumoin, Fabrice Guiziou, et al.. Correlation of chemical composition and odor concentration for emissions from pig slaughterhouse sludge composting and storage. Chemical Engineering Journal, 2015, 276, pp.398-409. 10.1016/j.cej.2015.04.031 . hal-01146565

HAL Id: hal-01146565

https://hal-univ-rennes1.archives-ouvertes.fr/hal-01146565

Submitted on 4 Nov 2015

HAL is a multi-disciplinary open access archive for the deposit and dissemination of scientific research documents, whether they are published or not. The documents may come from teaching and research institutions in France or abroad, or from public or private research centers.
L'archive ouverte pluridisciplinaire HAL, est destinée au dépôt et à la diffusion de documents scientifiques de niveau recherche, publiés ou non, émanant des établissements d'enseignement et de recherche français ou étrangers, des laboratoires publics ou privés. 
1 Correlation of chemical composition and odor concentration for emissions from pig

2

5

\title{
slaughterhouse sludge composting and storage
}

\author{
V. Blazy* ${ }^{\mathrm{A}}$, A. De-Guardia ${ }^{\mathrm{A}}$, J.C Benoist ${ }^{\mathrm{A}}$, M. Daumoin ${ }^{\mathrm{A}}$, F. Guiziou ${ }^{\mathrm{A}}$, M. Lemasle $^{\mathrm{B}}$,
}

D. Wolbert ${ }^{\mathrm{B}}$, S. Barrington ${ }^{\mathrm{A}, \mathrm{C}}$,

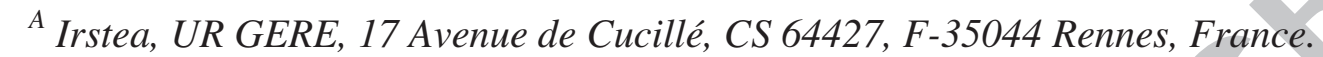

${ }^{B}$ Laboratoire Sciences Chimiques de Rennes - équipe Chimie et Ingénierie des Procédés,

UMR 6226 CNRS, ENSCR, Avenue du Général Leclerc, 35700 Rennes, France.

${ }^{C}$ Concordia University, Department of Building, Civil and Environmental Engineering, 1455 de Maisonneuve, Montréal, QC H3G 1M8, Canada.

*Corresponding author: Phone: +33299 2991 57; fax: +332234821 15.

E-mail address: vincent.blazy@irstea.fr (V. Blazy)*, amaury.de-guardia@irstea.fr (A. De-

Guardia), jean-claude.benoist@irstea.fr (J.C. Benoist), mylene.daumoin@irstea.fr (M.

Daumoin, France), fabrice.guiziou@irstea.fr (F. Guiziou), marguerite.lemasle@ensc-

rennes.fr (M. Lemasle), dominique.wolbert@ensc-rennes.fr (D.Wolbert),

suzellebarrington@sympatico.ca (S. Barrington).

\section{Abbreviations :}

BA, bulking agent ; $\mathrm{CH}_{3} \mathrm{SH}$, methanethiol ; GC-MS, gas chromatograph coupled with a mass spectrometer ; $\mathrm{H}_{2} \mathrm{~S}$, hydrogen sulfide; MDL, sampling and GC-MS method detection limit; $\mathrm{NH}_{3}$, ammonia ; OAV, odor activity value of a gaseous odorous compound defined as the ratio of its concentration to its odor detection threshold; OC, odor concentration of a gas volume measured by olfactometry and corresponding to the number of dilution required in order its odor is not detected anymore ; $\mathrm{OC}_{\mathrm{INT}}$, bound of the confidence interval of the odor concentration measure, $\mathrm{OAV}_{\mathrm{MAX}}$, odor activity value of the compound exhibiting the highest concentration to ODT ratio in a gaseous mixture; $\mathrm{OAV}_{\mathrm{MAX} 2}$ : odor activity value of the compound exhibiting the second highest concentration to ODT ratio in a gaseous mixture; $\mathrm{OAV}_{\mathrm{SUM}}$, summation of the odor activity values of every odorous compound contained in a gaseous mixture ; ODT, odor detection threshold ; PSS, pig slaughterhouse sludge ; RSH, mercaptan ; TMA, trimethylamine ; RD, Relative Deviation; VOC, volatile organic compound. 
8

\section{Abstract}

The objective of this study was to correlate the chemical composition and the odor concentration of emissions produced during storage and composting of pig slaughterhouse sludge (PSS). Seven experimental conditions were monitored using composting reactors with forced aeration and cells designed to simulate storage. Sixty six gas samples were collected and characterized by both GC-MS and olfactometry. Two types of correlation were investigated between the chemical composition and the odor concentration (OC) of every gas sample. The odor activity value for a given emitted compound (OAV) was computed as the ratio of its chemical concentration to its odor detection threshold (ODT). The correlation $\mathrm{OAV}_{\mathrm{MAX}}$ considered that the $\mathrm{OC}$ of a gas sample was equal to its highest OAV whereas the correlation $\mathrm{OAV}_{\mathrm{SUM}}$ considered that the odor of the gas sample was equal to the sum of the OAV of every compound contained in the gas sample. As per Standard EN 13725, both OAV MAX and $\mathrm{OAV}_{\text {SUM }}$ were compared using a confidence level for $\mathrm{OC}$ defined as [OC/1.65 to $1.65 \mathrm{x} \mathrm{OC}]$. Whereas $\mathrm{OAV}$ MAX values were within the confidence level of OC for $62 \%$ of the 66 gas samples, OAV confidence level for only $53 \%$. Validating $\mathrm{OAV}_{\mathrm{MAX}}$ as a satisfying correlation between chemical composition and OC, only three compounds among the 66 identified namely trimethylamine, hydrogen sulfide and methanethiol, accounted for the prediction of OC measured during composting and storage of PSS. 


\section{Highlights}

PSS composting and storage gas samples were determined by chemical and olfactory analyses

For gas samples, correlations between the chemical composition and its OC was investigated

$\mathrm{OAV}_{\mathrm{MAX}}$ assumed that $\mathrm{OC}$ was equal to the sample's highest $\mathrm{OAV}$ value

$\mathrm{OAV}_{\text {SUM }}$ assumed that $\mathrm{OC}$ was equal to the sum of all OAV for sample

The 3 most odorant compound offered a good prediction of the olfactory results.

Keywords: gaseous emission, odor, chemical composition, composting, storage, pig slaughter house sludge

\section{Introduction}

Odor emissions from composting plants are a common source of annoyance. Odorous nuisance can have significant impact on environmental health [1] and the quality of life. Negative neighbourhood reactions to composting odors may lead to temporary or definite closure and a lack of acceptance of new facilities [2]. Good management of composting operations can help minimize odor impacts, although odor generation cannot be avoided [3]. Odor management should take into account operational conditions such as composting facility aeration process, levels of confinement, emission sources identification, collecting and treatment of gaseous emissions [4]. Such difficulties in controlling compost facility odor nuisance demonstrate the lack of efficiency of present and often expensive solution technologies. 
Cost-effective strategies for solving odor problems require the identification of the major contributing odorants compounds as found in the gaseous mixture released [5]. This requires the correlation of the emission's chemical composition and its odor concentration. Targeting the most responsible compounds, such correlation can provide criteria for the development of: i) odor prevention and abatement strategies; ii) odor characterization using analysis of specific indicator compounds, and; iii) specific sensors for online odor monitoring.

The first main step towards linking the chemical composition of a sample and its odor concentration is to define how to integrate the odorous potential of an individual compound in a complex odor mixture. Indeed, each compound contributes to a different extent to overall odor concentration [6]. Based on the odor detection threshold (ODT-the minimal concentration of a single compound which is perceived by $50 \%$ of the population), the odor activity value (OAV) has been widely used [6-11]. It was defined as the ratio of the chemical concentration to the odor detection threshold of a single targeted compound within a sample. The odor activity value is a dimensionless value also interpreted as the theoretical dilution factor required to reach the odor detection threshold of the compound. Thus, the first step in achieving this correlation consists in linking the odor activity value of individual compound (or their theoretical dilutions factors) to the dilution factor required by olfactometry to reach the threshold dilution for the complex emission. This dilution factor is equivalent to its odor concentration, or OC, as defined by EN 13725 [12]. A first mathematical function used to correlate the odor activity value (OAV) and the odor concentration $(\mathrm{OC})$ consisted in numerically adding the $\mathrm{OAV}$ of all individual compound identified in the emission $\left(\mathrm{OAV}_{\text {SUM }}\right)$. The value $\mathrm{OAV}_{\text {SUM }}$ was used by Gallego et al. [11] to 
predict the concentration of composting odors in the absence of olfactometry. For odorous emissions produced by food and industrial wastes, Kim and Park [9] found a strong correlation between $\mathrm{OC}$ and $\mathrm{OAV}_{\mathrm{SUM}}$. In contrast, for odor emissions from cattle shelters, Parker et al. [6] found a poor correlation $\left(\mathrm{R}^{2}=0.16\right.$ to 0.52$)$ between $\mathrm{OC}$ and $\mathrm{OAV}$ SUM. Taking into account potential synergic effects between a large numbers of compounds, multivariate analyses coupled with regression methods were widely investigated. These complex methods were directly used by: Noble et al. [13] for mushroom composting; Hanajima et al. [14] for swine manure; Mao et al. [15] and Tsai et al. [2] for food waste, and; Defoer et al. [16] for green waste. Multivariate analyses were also used to correlate odor to odorant compounds for swine facilities [17-18] or the headspace above stored slurry [19-20]. These investigations produced no clear correlation allowing for the prediction of composting or livestock odor. Indeed, each model led to a specific relationship [16] and moreover, showed no cause-and-effect relationship [5] between the odor concentration and the chemical composition of the gaseous samples. These drawbacks indicated the complexity of the human sensory perception and the limits of these methods.

The objective of this study was to find a simpler and generic model to correlate the chemical composition and the odor concentration of emissions produced during composting under forced aeration and during storage. Pig slaughterhouse sludge (PSS) was the waste studied in this experiment. Seven laboratory experiments were monitored to simulate composting and storage of PSS. Sixty six gas samples were collected and characterized by both GC-MS and olfactometry. Two types of correlation were investigated to link the chemical composition and the odor concentration (OC) of every gas sample: the first was the sum of the odor activity values $\left(\mathrm{OAV}_{\mathrm{SUM}}\right)$, defined earlier, and; the second was 
$\mathrm{OAV}_{\text {MAX }}$ consisting of the highest $\mathrm{OAV}$ value associated with an individual compound within the sample.

\section{Materials and methods}

\subsection{Experimental conditions}

The composting experiments were performed in $300 \mathrm{~L}$ reactors consisting of insulated stainless cylinders, $800 \mathrm{~mm}$ in height and $700 \mathrm{~mm}$ in diameter. Immediately after loading the reactors, a low aeration rate of $1.3 \mathrm{~L} \cdot \mathrm{h}^{-1} \cdot \mathrm{kg}^{-1}$ of wet sludge was applied during 5 days. Thereafter, the aeration rate was increased to $9.3 \mathrm{~L} \cdot \mathrm{h}^{-1} \cdot \mathrm{kg}^{-1}$ wet sludge and maintained constant till the end of the experiment. A rotameter (FL-821-V, OMEGA Engineering Inc., Stamford, USA) regulated the in-coming airflow while a volumetric gas meter measured the flow (Gallus 2000,Actaris, Liberty Lake, USA). The reactor were equipped to continuously monitor the compost temperature and its total mass using respectively two Pt100 probes and weigh sensors. Concentrations in $\mathrm{O}_{2}$ and $\mathrm{CO}_{2}$ were continuously measured in both the in-coming and out-going airflows using respectively a paramagnetic analyzer (MAGNOS 206, ABB, Zurich, Switzerland) and an IR spectrometric analyzer (URAS 26, ABB, Zurich, Switzerland). Every 10 days, the compost was turned. The composting treatment was stopped after 36 days.

The composting experiments were carried out using PSS mixed with bulking agent. The sludge was collected from the primary wastewater treatment process of a pig slaughterhouse. The primary pig slaughterhouse sludge had collected at the plant, following 
its sieving using $6 \mathrm{~mm}$ and $1 \mathrm{~mm}$ sieves, its coagulation and flotation, and its centrifugation. At the laboratory, the sludge was stored in bags at $-18^{\circ} \mathrm{C}$. The content of each bag was dumped into opened bins to be thawed at $4^{\circ} \mathrm{C}$, one week before being used. The bulking agent (BA) consisted of oak and ekki wood chips with a particle size ranging from 0 to $40 \mathrm{~mm}$. The characteristics of the feedstock (pig slaughterhouse sludge plus wood chips) are provided in the supplementary materials 1 . The wet mass BA/PSS ratios applied were respectively 0.55 and $0.73 \mathrm{~kg} \cdot \mathrm{kg}^{-1}$. For a BA/PSS of $0.73 \mathrm{~kg} \cdot \mathrm{kg}^{-1}$, the two moisture contents tested were $61.2 \%$ to $63.7 \%$.

The storage cells were $28 \mathrm{~L}$ airtight stainless steel cylindrical vessels, with a height of $900 \mathrm{~mm}$ height and a diameter of $200 \mathrm{~mm}$. The cover of the storage vessel was equipped with an air inlet and outlet to sample the volume over the stored material. Each vessel was filled with $720 \mathrm{~mm}$ of PSS with and without BA. A constant aeration rate of $40 \mathrm{~L}^{-\mathrm{h}^{-1}}$ was applied to the cell, for a value of 1.72 to $3.95 \mathrm{~L} \cdot \mathrm{h}^{-1} \cdot \mathrm{kg}^{-1}$ of wet material. The gas samples were collected by connecting bags to the storage vessel ventilation exhaust port. The vessels were emptied after 14 to 30 days of storage.

The storage vessels were filled with fresh PSS, fresh PSS mixed with BA, and PSS composted for 15 and 30 days. The PSS composts were obtained from the composting experiments carried out with a BA/PSS ratio of $0.83 \mathrm{~kg} \cdot \mathrm{kg}^{-1}$ and under an aeration rate of 6.05 L.h $\mathrm{h}^{-1} \cdot \mathrm{kg}^{-1}$ of wet sludge. For the storage experiments with PSS composts, the larger wood chip particles were removed from the PSS + BA composted mixture using a rotary sieve with $10 \mathrm{~mm}$ openings. 
Table 1

Mixtures compositions and experimental conditions

2.2. Gas sampling, pre-dilution and preparation before odor measurement The samples were collected manually using single-use Nalophan bags (EN13 725 [12]), with a volume of 35 to $70 \mathrm{~L}$, depending on the expected odor concentration. Nalophan bags were directly connected to the reactor exhaust or to the storage vessel sampling port. It took from 30 to 60 minutes to fill the Nalophan bags depending on their volume and the treatment aeration rate. A glass bottle condenser was placed between the reactor exhaust and the bag used for sampling, to remove condensate, during the initial period of composting when hot moist gases were released. Gaseous emissions were sampled every two days from the start, still the end of each experiment. For each sampling session, two to three Nalophan bags were filled to duplicate or triplicate the measurement results. The analysis of several samples at any given time enhanced the accuracy of the odor concentration measurements.

To limit deterioration, chemical composition and odor concentrations measurements were conducted within 4 to 6 hours of collection. When possible, both analyses were carried out in less than few hours. The removal of water before sampling and the use of sampling bags could lead to odorant losses [8, 21], and consequently odor emission underestimation. It has been demonstrated that sample odor decreased when stored over 24 hours. Indeed, the recovery of odorants stored in sampling Tedlar bags [22-23-24], or Tedlar versus Nalophan [25-26-27] was analyzed after 4 to 24 hours, to show that most odorants can be lost after 24 hours [12]. Less than 5 and $10 \%$ of the odor of methanethiol, 
dimethyl sulfide and hydrogen sulfide was lost respectively in Tedlar and Nalophan bags, after 4 to 8 hours of storage [25-26-27]. Even though the recovery of odorants in sampling bags is an important issue and can lead to odor concentration underestimation, Van Harreveld [28] showed that odor is stable in Nalophan bags for a period of 4 to 12 hours. Since sample bags were analyzed within 4 to 6 hours and because of similar treatment, chemical composition and odor concentration from the same sampling bag could be compared and considered to represent the emission sampled.

Since gaseous emissions from the raw compost required a large dilution level before olfactometry, namely 131,000 folds, samples had to be pre-diluted, using three methods providing a range of 12.6 to 500 . The first method consisted in directly connecting to the olfactometer, a double orifice probe mixing the gas sample with dry clean air, where the size of the respective orifices provided a dilution ratio of 100 . The dilution rate of the probe was controlled using a Gilibrator 2 calibration system (Gilian, Clearwater, USA). The second method consisted in precisely measuring $250 \mathrm{~mL}$ of gas sample using a glass sampling bulb with a PTFE stopcock (Supelco, Bellefonte,USA). Using the olfactometer, the $250 \mathrm{ml}$ volume was then injected into a Nalophan bag containing 5, 30 or $35 \mathrm{~L}$ of dry clean air for a dilution rate of respectively of 21,121 or 141 . Thus, the accuracy of the dilution was determined by that of the olfactometer airflow controls. The third dilution method consisted in withdrawing a diluted sample from a Nalophan bag using a gas tight syringe (Supelco) and then injecting into a new Nalophan bag filled with a known volume of clean air. The pre-diluted rate was applied to the odor concentration level measured by olfactometry. According to Wardencki [29], the collection and storage of gas samples in a glass bulb leads to a significant loss of hydrogen sulfide and methanethiol. However, in this 
study, glass bulbs or glass syringes were sparsely used even to stored samples for less than few minutes before being mixed with dry and odorless gas in Nalophan bags. Moreover, as described below for the composting experiments, a glass condenser preceded the hydrogen sulfide and mercaptan traps. Because a similar treatment was used for all samples, hydrogen sulfide and mercaptan odor concentration could be compared.

When possible, a pure and a pre-diluted bag were analyzed to verify the dilution accuracy and adjust the dilution coefficient for olfactometric characterization. This coefficient was computed by dividing the carbon mass from each compound of the two bags. Pre-dilution factor ranged from $3 \%$ to $39 \%$ with a mean value of $19.5 \%$, and the use of a correction factor improved the accuracy of the pre-dilution procedure. However, the relative OC deviation measured between two pre-diluted bags from the same sample ranged from 0 to $20.8 \%$ with a mean value of $10.3 \%$ against $9.8 \%$ for the bags analyzed without pre-dilution. This low difference showed that even though the accuracy of the pre-dilution methods had to be corrected, their repeatability was quite satisfactory (data not shown). In decreasing order, the accuracy of the dilution methods are: gas tight syringe; glass sampling bulb, and; dilution probes. Since many samplings required a dilution factor of over 100 , the glass sampling bulb was mostly used. The tight syringe was used only once for each composting reactors, just before the composting airflow adjustment because of the low aeration rate resulting in highly concentrated samples required a dilutions factor of 200 to 500.

\subsection{Olfactory measurements}


The dynamic dilution olfactometer ONOSE-8 (Consumaj, Canada) was used to determine the odor concentrations (OC) of the studied samples. The Onose- 8 olfactometer was designed to respect the EN 13725 [12] standards. The apparatus was calibrated using the Gilibrator 2 calibration system (Gilian, Clearwater, USA) which handles a wide range of flow rates.

The olfactory method consisted in firstly applying a dilution rate to the gas sample high enough not to be detected by the 6 panellists. Then, the dilution rate was reduced until odor was detected. The mass flow controllers of the ONOSE-8 provide a dilution scale ranging from 16 to 131 000. Triple force-choice was the principle used where all trained panelists have to identify among three ports that contaminated. The panelist group consisted of 19 persons, each being selected based on their sensitivity to the n-butanol reference gas as described in the EN 13725 [12] standards. At least 6 odor panelists were selected for each olfactometric session. Each bag, even from identical sampling, was presented three times to the panel. The first presentation used a dilution step factor of 4 , to rapidly introduce the panelists to the odor stimuli. The result of this presentation was systematically removed and not considered. Then, two additional series of ascending concentration ratios with a step factor of 2 were presented to prevent olfactory adaptation or a loss of sensitivity. The geometric mean of the panel detection thresholds from these two series was used to compute the odor concentration of the sub-sample contained in the bag. The final odor concentration of the gas sample, expressed in OU.m ${ }^{-3}$, was the geometric mean of the odor concentrations of the 2 to 3 bags analyzed. All the odor concentrations of each sample analyzed are shown in the supplementary material 2. According to Hansen et al., [30-31], olfactometer dilution systems can alter the odorous charge of a compound. Reduced sulfure 
compounds, such as hydrogen sulfide, methanethiol and dimethyl sulfide, can be affected differently when flowing through the olfactometer system, as they can suffer an average loss of $55-60 \%, 27-35 \%$ and $9.3-21 \%$, respectively. Furthermore, the recovery of other odorants, such as carboxylic acids, trimethylamine and 3-methylphenol, were also significantly affected by the pulse duration leading to unstable signals within the 60 -second pulse. Although such losses were not investigated in this study, the Onose-8 olfactometer offers accurate mass flow controllers with a limited error margin of $\pm 0.2 \%$ (0\% to $20 \%$ of the total range) and $\pm 1 \%$ ( $20 \%$ to $100 \%$ of the total range). Moreover, panelists were invited to detect the odorous stimulus after the mass flow controllers showed a stable signal. This precaution favors odorant recovery.

\subsection{Chemical characterization of gases}

\subsubsection{Quantification of $\mathrm{NH}_{3}, \mathrm{H}_{2} \mathrm{~S}$ and mercaptans emissions}

Using airflow taps on the gas exhaust lines after the glass condenser, two gas lines were placed in parallel: the first to trap ammonia $\left(\mathrm{NH}_{3}\right)$ in sulfuric acid $\left(\mathrm{H}_{2} \mathrm{SO}_{4}, 1 \mathrm{~N}\right)$, and; the second to trap in series, hydrogen sulfide $\left(\mathrm{H}_{2} \mathrm{~S}\right)$ in a formic/formate acid buffer solution $0.1 \mathrm{~N}$ with $10 \mathrm{mg} . \mathrm{L}^{-1}$ lead nitrate $\left(\mathrm{PbNO}_{3}\right)$, and then mercaptans $(\mathrm{RSH})$ in acid $(0.1 \mathrm{~N})$ with $10 \mathrm{mg} . \mathrm{L}^{-1}$ mercuric dichloride $\left(\mathrm{HgCl}_{2}\right)$. The aeration rate through each line, namely for the $\mathrm{NH}_{3}$ and $\mathrm{H}_{2} \mathrm{~S}$ traps, followed in series by the RSH trap, was fixed by a flow meter (FL-821-

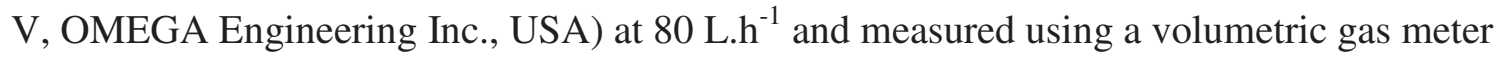
(Gallus 2000, USA). 
For the $\mathrm{NH}_{3}$ traps, $\mathrm{NH}_{4}{ }^{+} / \mathrm{NH}_{3}$ content was quantified by steam distillation (method modified from NFT 90-015-1 [32], Gerhardt Vapodest 50, Germany) into boric acid $\left(\mathrm{H}_{3} \mathrm{BO}_{3}, 40\right.$ g.L $\left.\mathrm{L}^{-1}\right)$ and then back-titration with sulfuric acid $\left(\mathrm{H}_{2} \mathrm{SO}_{4}, 0.2 \mathrm{~N}\right)$. Duplicate results were validated by a coefficient of variation below $5 \%$. The titration detection limit was $0.014 \mathrm{mgN} . \mathrm{mL}^{-1}$ of trap. Considering the mean trap volume of $200 \mathrm{~mL}$ at a density of 1023 g.m $\mathrm{m}^{-3}$ during a sampling period of $24 \mathrm{~h}$, the method detection limits for ammonia in the exhaust gas was $0.286 \mathrm{mg} \cdot \mathrm{m}^{-3}$. The reaction of $\mathrm{H}_{2} \mathrm{~S}$ with $\mathrm{PbNO}_{3}$ and of $\mathrm{RSH}$ with $\mathrm{HgCl}_{2}$ produced a $\mathrm{PbS}$ and $\mathrm{Hg}(\mathrm{SR})_{2}$ precipitate recovered by filtration through glass fibre filters (Satorius, France). The precipitates were dried at $55^{\circ} \mathrm{C}$ and weighed. In this study, all mercaptans emissions trapped in $\mathrm{HgCl}_{2}$ were calculated as methanethiol leading to $\mathrm{Hg}\left(\mathrm{SCH}_{3}\right)_{2}$ precipitate. This potentially led to under-estimating the odor contribution of mercaptans since the odor detection threshold of methanethiol is higher than that of other mercaptans such as ethanethiol, propanethiol, and 1- butanethiol. The concentrations of the compounds analysed by chemical traps was computed as the mean values of their emissions between two odor sampling sessions.

For the composting experiments, the traps were changed every $24 \mathrm{~h}$ for the first 15 days and then every time the gas was sampled for odor measurement. For the storage experiments, the traps were also changed every time the gas was sampled for odor measurement, namely every two days. Saturation was never observed for the $\mathrm{NH}_{3}, \mathrm{H}_{2} \mathrm{~S}$ and RSH traps. 


\subsubsection{VOCs identification and quantification}

The chemical gas samples characterization included the identification and the quantification of VOCs. Thus, the gas samples collected in Nalophan bags were concentrated by passing through Carbotraps (Carbotrap 349, PerkinElmer, USA) using a vacuum pump (Giliar, USA) equipped with a constant low flow module set at $50 \mathrm{~mL}, \mathrm{~min}^{-1}$. Considering that VOCs concentrations were unknown, several Carbotraps were prepared for each sample by passing different volumes, namely 500, 1000, 1500, $3000 \mathrm{~mL}$. Accordingly, such volumes were associated with detection limits of 80, 40, 26 and 13 $\mu \mathrm{g} \cdot \mathrm{m}^{-3}$, respectively. The Carbotraps were stored at $4^{\circ} \mathrm{C}$ for less than one week before being desorbed and analyzed by GC-MS [33].

The desorption was carried out by a Thermal Desorption unit (TurboMatrix 550, Perkin Elmer) coupled with a Clarus 500 GC-MS detector (Perkin Elmer). Then, these were separated through the capillary column (CP-WAX 58, 25m x 0.15mm; Film 0.25 Varian, USA). Analytical conditions of thermal desorption and column separation, were provided by Blazy et al. [34]. Chromatogram processing depended on the detection mode used by mass spectrometry for detecting separated compounds. Indeed, 2 simultaneous acquiring modes were used. A full scan (FS) acquisition (20-300 amu) allowed for the identification of compounds with 2 sets of criteria: (1) GC retention times and mass spectra matched with

the calibrated compounds, and; (2) the mass spectra obtained from a reference library (National Institute of Standards and Technology, NIST, Gaithersburg, USA). A quantitative assessment of VOCs was performed by a single ion resolution (SIR) acquisition which quantified specific masses of compounds ( $\mathrm{m} / \mathrm{z}$, major characteristic ion in the spectra) as 
area counts under peaks for separated VOCs. A calibration was performed to convert the measured area into a compound mass.

The calibration procedure consisted in injecting into an $\mathrm{N}_{2}$ filled Tedlar bags, a known volume of the compound of high purity (Acros Organics, Alfa Aesar or Sigma Aldrich) at a concentrations of 13 to $5000 \mu \mathrm{g} \cdot \mathrm{m}^{-3}$. According to the method described previously, each bagged compound was trapped onto a Carbotrap and thereafter analyzed by GC-MS. The fact that the Tedlar bags could not recovery the total amount of injected compound lead to an underestimation of the GC-MS quantification. Finally, the calibration curves were obtained by plotting the GC integrated areas versus the concentration of the bagged compound. A linear regression curve was obtained with the calibration data, except with light amines at low concentrations because of their poor detection by GC-MS, as expected. This process also demonstrated that the thermal desorption allowed to recover a very high percentage of the trapped VOCs.

The GC-MS was not calibrated for all identified compound. Non calibrated compounds were quantified by assuming a response factor equal to 1000 , which represents the average value obtained with all of the calibrations.

\section{Results and discussion}

\subsection{Determination and evaluation of odor activity}

The GC-MS analysis of the 66 samples yielded 39 compounds presented in the Table 2 along with: their CAS (Chemical Abstracts Service) number; the ion used for their quantification; whether or not they associated with a calibration procedure and; their odor 
detection thresholds (ODT) as per a recent database [36]. When several odor detection thresholds were available for a single compound, only the most recent value was used. In general, recent odor detection threshold values were lower than the old ones, leading to higher odor activity values. However, the order of magnitude for many individual compounds could be considerably different [6-11]. According to Parker et al [6], the central tendency of the odor detection threshold values was well descript by geometric means compared to harmonic means (which were lower) and arithmetic means (which were higher and influenced by the larger individual values). Thus when several recent odor detection threshold values were available, a geometric mean was used in order to obtain a central tendency of the odor activity value.

As highlighted for some compounds in Table 2, the GC-MS detection level (method detection limit or MDL) was higher than the odor detection threshold, leading for some samples, to the under-estimation of the odor activity value. In Table 2 , the ratio $\left(\mathrm{MDL}_{\mathrm{MAX}}\right) / \mathrm{ODT}$ indicates the level of underestimation for these compounds, where MDL $_{\text {MAX }}$ is the highest method detection limits observed during samples according the gas volume passed throughout Carbotraps. Nevertheless, only trimethylamine (TMA) showed an important odor activity value underestimation, with an $\mathrm{MDL}_{\mathrm{MIN}} / \mathrm{ODT}$ and MDL $_{\text {MAX }}$ /ODT ranging between 217 and 11333, respectively. Sulfurs, aldehyde and alcohol compounds showed a maximal OAV underestimation of around 10, or even less. For such compounds, the method detection limits showed low underestimation of odor activity value determination.

\section{Table 2}


Gaseous compounds identified from emissions collected during the composting and the storage of pig slaughterhouse sludge

A last and important bias for odor activity value determination can result from the use of sorbent tubes and the subsequent thermal desorption in TD-GC/MS. Indeed, mercaptans and especially methanethiol can be oxidized to form di- and tri-sulfides [59] which were largely quantified during chromatogram processing. This reinforces the assumption that mercaptan were mainly methanethiol. Consequently, the odor activity value from methanethiol could double when adding the odor activity value from organo-sulfides, thus leading to odor activity values overestimation. However, the source of the organo-sulfide was uncertain, whether from composting or from mercaptan oxidization, or from a combination of both.

For every compound, its odor activity value (OAV) was calculated from the ratio of its chemical concentration to its odor detection threshold. All the chemical concentrations and OAV are provided in Supplementary Materials 3 and 4, respectively. The odor activity values of methenamine, 1,3 pentadiene and 3-pentanone-2-methyl were not calculated because of their unknown odor detection threshold.

Two correlations were calculated to link gas sample odor concentration (OC) to its chemical composition: $\mathrm{OAV}_{\mathrm{MAX}}$, assuming that odor concentration is equal to the $\mathrm{OAV}$ of

the most odorous compound, and; $\mathrm{OAV}_{\mathrm{SUM}}$, assuming that odor concentration is equal to the sum of all compound OAV. The values of OC, and $\mathrm{OAV}_{\operatorname{MAX}}$ and $\mathrm{OAV}_{\operatorname{MAX} 2}$ (the first and second highest odor activity value per sample) and $\mathrm{OAV}_{\mathrm{SUM}}$ are given in Supplementary Material 4. 
The relevance of the two types of correlation was evaluated based on the percentage by which $\mathrm{OAV}_{\mathrm{MAX}}$ and $\mathrm{OAV}_{\mathrm{SUM}}$ fell within the $95 \%$ interval of confidence for the corresponding measured odor concentration (OC), as computed for every sample (EN 13725 [12]):

$$
\mathrm{OC} /\left(10^{2.0} * \mathrm{Sr} / \sqrt{n}\right)<\mathrm{OC}<\mathrm{OC} *\left(10^{2.0} * \mathrm{Sr} / \sqrt{n}\right)
$$

with, $\mathrm{n}$ is the number of bags analyzed, from 1 to 3 , and $\mathrm{Sr}$ is the standard deviation calculated from the repeatability, namely 0.1721 . The mean value of $\left(10^{2.0} * \operatorname{Sr} / \sqrt{n}\right)$ was found to be 1.65 , whereby $\mathrm{OC} / 1.65<\mathrm{OC}<\mathrm{OC} \times 1.65$.

Consequently, each odor concentration (OC) measure is linked to: two boundaries of the confidence interval as above-mentioned, the highest odor activity value $\left(\mathrm{OAV}_{\mathrm{MAX}}\right)$ (resulting from a single compound) and the sum of the odor activity values from all compounds in the gas sample $\left(\mathrm{OAV}_{\mathrm{SUM}}\right)$.

The correlation extent between $\mathrm{OC}$ and either $\mathrm{OAV}_{\mathrm{MAX}}$ or $\mathrm{OAV}_{\mathrm{SUM}}$ was estimated through a simple linear regression using a log transformation to limit distribution variance between the variables $\left(\mathrm{OAV}_{\mathrm{SUM}}, \mathrm{OAV}_{\mathrm{MAX}}\right.$ and $\left.\mathrm{OC}\right)$. This log transformation better illustrated data patterns and allowed for the use of a simple correlation type $\log \left(O A V_{\text {MAX }}\right)$ or $\log \left(\mathrm{OAV}_{\text {SUM }}\right)=1 \log (\mathrm{OC})$ to link the variables. The logarithmic expression of the odor concentration should not be considered as an indirect indicator of the odor intensity, and extension of odor concentration. Moreover, using a "log-log correlation" graphically favors a closeness between $\mathrm{OC}$ and $\mathrm{OAV} \mathrm{V}_{\mathrm{MAX}}$ or $\mathrm{OAV}_{\mathrm{SUM}}$, especially for high values of OC. Therefore, the relevance of $\mathrm{OAV}_{\text {SUM }}$ and $\mathrm{OAV}_{\mathrm{MAX}}$ predictions were also estimated on the basis of the Relative Deviation, computed for the mixtures showing an $\mathrm{OAV}_{\mathrm{MAX}}$ or 
402

403

404

405

406

407

408

409

410

411

412

413

414

415

416

417

418

419

420

421 of $5.6 \%$, indicating a limited influence of method detection limits on OAV $\mathrm{V}_{\text {SUM }}$

422 determination.

$\mathrm{OAV}_{\text {SUM }}$ prediction outside the confidence interval of odor concentrations. Values for Relative Deviations (RDs) were computed with the closest odor concentration interval bounds $\left(\mathrm{OC}_{\mathrm{INT}}\right)$ according to the Eq.1:

$$
\mathrm{RD}=\left(\mid \mathrm{OAV} V_{\mathrm{MAX}} \text { or } \mathrm{OAV}_{\mathrm{SUM}^{-}}-\mathrm{OC}_{\mathrm{INT}} \mid\right) * 100 / \mathrm{OC}_{\mathrm{INT}}
$$

with $\mathrm{OC}_{\mathrm{INT}}$ being the closest interval bounds of $\mathrm{OAV}_{\mathrm{MAX}}$ or $\mathrm{OAV}_{\mathrm{SUM}}$, in OU.m ${ }^{-3}$, and where $\mathrm{OAV}_{\text {MAX }}$ and $\mathrm{OAV}_{\text {SUM }}$ are dimensionless. Values for Relative Deviation (RD) are found in Supplementary Material 5 and expressed in \%. A box plot figure was drawn to study the distributional characteristics of the RD of $O A V_{\text {MAX }}$ and $O A V_{\text {SUM }}$ predictions with $\mathrm{OC}_{\mathrm{INT}}$.

affected by underestimation resulting from method detection limit. Therefore, the influence of the method detection limits on $\mathrm{OAV}_{\text {SUM }}$ computations was investigated. The maximum underestimated odor activity value is computed (supplementary material 4), defined as the ratio between the method detection limits by the odor detection threshold of the compounds, and added in the $\mathrm{OAV}_{\mathrm{SUM}}$ computation. The method detection limits was observed to produce 0 to $55 \%$ deviation on the sum of the odor activity values (supplementary material 4). Trimethylamine has a very low odor detection threshold mainly involved in the determination of $\mathrm{OAV}_{\mathrm{SUM}}$. However, the mean Relative Deviation between the computed $\mathrm{OAV}_{\mathrm{SUM}}$ (with or without taking in account the method detection limit) was 
3.2. Qualitative evaluation of the highest odor activity value and the sum of the odor activity value from a gas sample

Olfactometry consists initially in diluting a gas sample until its odor cannot be perceived by all panellists, and then, increasing its concentration, with lower dilutions, until all trained human panelists are able to detect the odor. Theoretically in the absence of synergistic effects, the olfactory stimulus should come from the most odorant compound namely the one requiring the highest dilution rate to be odorless. In this context, Zahn et al. [60] showed that the synergistic effects were minor for swine odors. Thus, odor concentration should correlate to the odor activity value of the most odorant compound namely $O A V_{\text {MAX }}$. Considering the 66 gas samples analyzed, OAV $V_{\text {AXX }}$ displayed only three compounds responsible for the odors, namely mercaptans (presumed to be methanethiol), trimethylamine and hydrogen sulfide, respectively at 64,21 and $15 \%$ of the gaseous mixtures studied. Similarly by multivariate analyses, Hansen et al. [18] identified hydrogen sulfide, methanethiol, trimethylamine, and 4-methylphenol as the main odorous compounds emitted from growing-finishing hogs facilities. Finally, these three compounds were presumed to be mostly responsible for odor concentration (OC) because of their very high odor activity values (OAV) in all 66 samples.

Fig. 1 gives $\log \left(\mathrm{OAV}_{\mathrm{MAX}}\right)$ values as function of $\log (\mathrm{OC})$. The dotted lines represent the $95 \%$ confidence interval for $\log (\mathrm{OC})$, namely $\log (\mathrm{OC} / 1.65)<\log (\mathrm{OC})<\log$ $(\mathrm{OC} * 1.65)$. The values for $\log \left(\mathrm{OA} \mathrm{V}_{\mathrm{MAX}}\right)$ fell outside this interval mostly for mixtures within methanethiol, estimated as the most odorous compound and especially at low and high concentrations, namely when $\mathrm{OAV}_{\mathrm{MAX}}$ was under $8 \times 10^{3}$ and over $6 \times 10^{4}$. This resulted either from the low relevance of the $\mathrm{OAV}_{\mathrm{MAX}}$ correlation for the low 
concentration, from the insufficient accuracy of the chemical characterization method (hydrogen sulfide and mercaptans samples correspond to that collected during almost $24 \mathrm{~h}$ while samples for odor concentration and GC/MS quantification were collected during less than one hour), or from the assumption that mercaptans were mostly methanethiol.

Nevertheless, the slope of the fitted line lies is very close to that of the confidence intervals with $\log \left(\mathrm{OAV}_{\mathrm{MAX}}\right)=0.98 \log (\mathrm{OC})$. Furthermore, the coefficient of determination $\left(\mathrm{R}^{2}=0.90\right)$ denoted a strong linear association between $\log \left(\mathrm{OAV}_{\mathrm{MAX}}\right)$ and $\log (\mathrm{OC})$, suggesting that $\log \left(\mathrm{OAV}_{\mathrm{MAX}}\right)$ could be a good predictor of $\log (\mathrm{OC})$.

\section{Fig. 1}

Predicted $\log \left(\mathrm{OAV}_{\mathrm{MAX}}\right)$ as function of measured $\log (\mathrm{OC})$; $O A V_{\text {MAX }}$ is the odor activity value (OAV) of the most odorous compound, namely the compound with the highest concentration/ODT value; OC was measured by olfatometry. Hollow points stand outside the confidence interval of OC.

Fig. 2 gives $\log \left(\mathrm{OAV}_{\mathrm{SUM}}\right)$ values as function of $\log (\mathrm{OC})$. As for $\log \left(\mathrm{OAV} \mathrm{V}_{\mathrm{MAX}}\right)$, $\log \left(\mathrm{OAV}_{\text {SUM }}\right)$ fell outside the $\log (\mathrm{OC})$ confidence interval mostly for mixtures where methanethiol was the most odorous compound and especially when at low and high concentrations, namely when $\mathrm{OAV}_{\mathrm{MAX}}$ was under $8 \times 10^{3}$ and over $6 \times 10^{4}$. As for $\log$ $\left(\mathrm{OAV}_{\mathrm{MAX}}\right)$, the slope of the fitted line was very close to that of the confidence interval, where $\log \left(\mathrm{OAV}_{\text {SUM }}\right)=1 * \log (\mathrm{OC})$, namely $\log \left(\mathrm{OAV}_{\text {SUM }}\right)=1.02 \log (\mathrm{OC})$, with a coefficient of determination $\mathrm{R}^{2}=0.87$. In conclusion, $\log \left(\mathrm{OAV}_{\mathrm{SUM}}\right)$ can also be an acceptable predictor of $\log (\mathrm{OC})$. 
470

471

472

473

474

475

476

477

478

479

480

481

482

483

484

485

486

487

488

489
Fig. 2

Predicted $\log \left(\mathrm{OAV}_{\mathrm{SUM}}\right)$ as function of measured $\log (\mathrm{OC})$; OAV $\mathrm{O}_{\text {SUM }}$ was obtained by summing the OAV of every odorous compound found in the gas sample; Odor concentration (OC) was measured by olfatometry. Hollow points are out of the confidence limits of the OC measure.

However to determine odor concentration, on basis of Fig. 1 and 2, OAV $\mathrm{MAX}_{\text {showed a }}$ higher coefficient of determination than $\mathrm{OAV}_{\mathrm{SUM}}$. Although $\mathrm{OA} \mathrm{V}_{\mathrm{MAX}}$ and $\mathrm{OAV}_{\mathrm{SUM}}$ are functions which are far apart, their linear regression shows a numerically similarity (Log $\left(\mathrm{OAV}_{\mathrm{SUM}}\right)=1.04 \mathrm{Log}\left(\mathrm{OAV}_{\mathrm{MAX}}\right)$ and $\mathrm{R}^{2}=0.98$; data not show $)$. Consequently, for most of the samples analyzed, the odor activity value (OAV) was mainly displayed by a single compound. In other words, a limited percentage of the odor activity charge is displayed by secondary compounds. Therefore, a quantitative study of OAV $\mathrm{OAX}_{\mathrm{X}}$ and $\mathrm{OAV}_{\mathrm{SUM}}$ correlation with the odor concentration must be investigated.

\subsection{Quantitative evaluation of odor activity}

Table 3 gives the numbers of samples where only $\mathrm{OAV}_{\mathrm{MAX}}$, only $\mathrm{OAV}_{\mathrm{SUM}}$ and when both values fell outside the $95 \%$ confidence interval of the odor concentration measurement. The mean of the absolute Relative Deviation value is also presented. 


\section{Table 3}

Comparison of the absolute Relative Deviation of $\mathrm{OAV}_{\mathrm{MAX}}$ and $\mathrm{OAV}_{\mathrm{SUM}}$ with respect to the $95 \%$ confidence interval for odor concentration measurement

The highest odor activity value in a gas sample $\left(\mathrm{OAV}_{\mathrm{MAX}}\right)$ was within the confidence interval of odor concentration (OC) for $62 \%$ gas samples (Fig. 1) whereas the sum of the odor activity values of a gas sample (OAV $\left.\mathrm{OUM}_{\mathrm{SU}}\right)$ for $52 \%$ (Fig. 2). For all the OAV $\mathrm{OAX}_{\mathrm{MAX}}$ and the $\mathrm{OAV}_{\mathrm{SUM}}$ outside the confidence interval, the mean Relative Deviations (RDs) were of 53 and $73 \%$, respectively. As result, the mean absolute RD value indicated that $O A V_{\text {MAX }}$ was, on the average, closer to the corresponding odor concentration interval than $O A V_{S U M}$. Similarly, when the mixtures showed that both, $O A V_{\text {MAX }}$ and $O A V_{\text {SUM }}$, were outside the confident interval of the odor concentration, the Relative Deviation remained lower for $\mathrm{OAV}_{\text {MAX }}$, namely at $68 \%$ versus $103 \%$ for $\mathrm{OAV}_{\text {SUM. }}$. Finally, the Fig. 3 shows the distributional characteristics of the Relative Deviation when the highest odor activity value $\left(O A V_{\text {MAX }}\right)$ and the sum of the odor activity values $\left(O A V_{S U M}\right)$ from a gas sample were outside the confident interval of the odor concentration measurement.

\section{Fig. 3}

Box plot of the Relative Deviation between the closest odor concentration interval boundaries $\left(\mathrm{OC}_{\mathrm{INT}}\right)$ and the maximal odor activity value within a sample outside the odor concentration confident interval, and; between $\mathrm{OC}_{\mathrm{INT}}$ and the sum of every odor activity values of a sample outside the odor concentration confident interval 
The range of Relative Deviation (RD) between the sum of the odor activity values from a gas sample $\left(\mathrm{OAV}_{\mathrm{SUM}}\right)$ and the closest odor concentration interval boundaries $\left(\mathrm{OC}_{\mathrm{INT}}\right)$ was larger than the range of RD between the highest odor activity value from a gas sample $\left(\mathrm{OAV}_{\mathrm{MAX}}\right)$ and $\mathrm{OC}_{\mathrm{INT}}$ (Fig. 3). The $\mathrm{OAV}_{\text {SUM }}$ varied from -73 to $300 \%$ against -80 to $200 \%$ for $\mathrm{OAV}_{\mathrm{MAX}}$. Moreover, $50 \%$ of the $\mathrm{OAV}_{\mathrm{MAX}}$ data set was displayed in a relative deviation interval of -33 to $45 \%$, whereas, for $\mathrm{OAV}_{\mathrm{SUM}}$, this interval ranged from 22 to $74 \%$. Since the Relative Deviation for $\mathrm{OAV}_{\mathrm{MAX}}$ was closer to $\mathrm{OC}_{\mathrm{INT}}$ than that computed for $\mathrm{OAV}_{\mathrm{SUM}}, \mathrm{OAV}_{\mathrm{MAX}}$ better predicted the odor concentration (OC) with $\mathrm{OAV}_{\text {SUM }}$ overestimating OC.

The Relative Deviation between OC and $\mathrm{OAV}_{\mathrm{MAX}}$ or $\mathrm{OAV}_{\mathrm{SUM}}$ was very high especially when OC was low, namely under $3 \times 10^{3}$ OU.m ${ }^{-3}$. Even if the statistical analysis of too few samples with such a low odor concentration was not possible, the following were investigated with no resulting conclusion: the influence on odors of some mitigating effects such as $\mathrm{NH}_{3}$ concentration [2]; the number of sample compounds with a concentration exceeding the odor detection threshold; the distribution of the odor activity value among compounds within the sample, such as $\mathrm{OAV}_{\mathrm{MAX}} / \mathrm{OAV} V_{\mathrm{MAX} 2}$ and as provided in the supplementary material 5), and; the closeness of the odor activity values among compounds (results not shown). Also, the relative deviation was influenced by: the method used for mercaptans analysis; the exclusion of compounds without known odor detection threshold; too high or too low a value for the geometric mean of odor detection threshold; the assumption that odor is linearly correlated to concentration, and; the negligible synergy assumed among odorous compounds. 
Limited research work correlates the highest odor activity values for a gas sample to its odor concentration. However, several studies correlated the odor intensity with respect of the VDI 3881 [61], ASTM E544-10 [62]) measured at supra-threshold with the theoretical intensity derived from compound concentration forming synthetic mixtures. Kim and Park [9] showed that odor intensity could be determined by a single predominant compound rather than by the sum or average of all individuals. Kim [63] and Zhao et al. [64] also found that the odor intensity from compound mixtures with similar chemical properties could be mostly characterized by averaging the odor intensity potential of all the contributors. The relevance of the "highest odor activity value compound model" must be cautiously considered as further investigation is necessary.

The literature has generally favoured the correlation between odor concentration (OC) and the sum of the odor activity values for a gas sample $\left(O A V_{S U M}\right)$ even if the numerical addition of odor activity value, representing the theoretical dilution factor, does not correspond to the method used in olfactometry. Kim and Park [9] found a strong correlation (Pearson coefficient of 0.866 ) between $\mathrm{OAV}_{\mathrm{SUM}}$ and $\mathrm{OC}$, without presenting sufficient data to appreciate the closeness between $\mathrm{OAV}_{\mathrm{MAX}}$ and $\mathrm{OAV}_{\mathrm{SUM}}$. Parker et al. [6] correlated OC to $\mathrm{OAV}_{\mathrm{SUM}}$, to find a 2 to 3 fold underestimation of OC. However, the range of measured odor concentrations was quite low, namely from $3 \times 10^{1}$ to $8 \times 10^{3}$ OU.m ${ }^{-3}$. In this range, OAV SUM can be easily underestimated, especially for compounds with a very low odor detection threshold. In this study, supplementary materials 4 lists all cases with compounds detected below their detection limits. Moreover, supplementary materials 4 presents the maximum odor activity value underestimation, defined as the ratio of the method detection 
limits by the odor detection threshold of the considered compound for each compounds and the sum of the odor activity value of a gas sample.

\subsection{Emissions profiles of odor concentration and the main odorous compounds}

Fig. 4a, 4b and 4c compares Log (OAV) and Log (OC) for the leading odorous compounds of the gas sample collected during the composting processes applied. As previously mentioned, the similarity between a sample's odor concentratin (OC) and its highest odor activity value $\left(O A V_{\text {MAX }}\right)$ or the sum of its odor activity values $\left(O A V_{S U M}\right)$ required a cautious interpretation because of the "log-log correlation". Nevertheless, the $\log \left(\mathrm{OAV}_{\mathrm{MAX}}\right)$ profile emissions (hollow points) better described Log $(\mathrm{OC})$ variations. For the first 4.6 days, $\mathrm{OAV}_{\mathrm{MAX}}$ was much lower than $\mathrm{OC}$ and methanethiol was the most odorant compound. Thereafter, $\mathrm{OAV}_{\mathrm{MAX}}$ followed, as expected, the same trend as OC and was relatively close, confirming that $\mathrm{OAV}$ MAX is a good predictor of OC. Then, hydrogen sulfide was found as the most odorous compound except for the samples on day 15 with a peak of trimethylamine, whatever the process conditions. The odor emissions decreased significantly after 15 to 20 days at which time no leading odorous compound could be clearly identified.

Accordingly, mercaptans were emitted when the need for $\mathrm{O}_{2}$ was highest and when the redox potential was the lowest whereas hydrogen sulfide was emitted at a slightly lower redox potential. Finally, the second and the third material turning operation, on days 22 and 29, influenced neither OAV $\mathrm{MAX}_{\text {na }}$ nor (Fig. $4 \mathrm{a}, 4 \mathrm{~b}$ and $4 \mathrm{c}$ ) emissions while an increase in
$\mathrm{O}_{2}$ consumption and temperature indicated that biodegradation was still in progress. Thus, 
the easily biodegradable fraction of organic matter, responsible for the highest $\mathrm{O}_{2}$ demand, seemed to produce conditions for the emission of the most odorous compounds.

The distribution of the odor activity value within a sample also indicates the perspectives for odor abatement, with the removal of the most odorous compounds not necessarily generating a strong odor decrease. The extent of the odor decrease will depend of the next highest odor activity value perceptible during odor concentration measurement. Consequently odor treatment must target in decreasing order, the compounds showing the highest odor activity value. Thus, the number of compounds to be targeted for odor abatement can vary greatly.

\section{Fig. 3}

Composting emissions profiles of odor concentration (OC) and odor activity value (OAV) for the leading odorous compounds, namely methanethiol $\left(\mathrm{CH}_{3} \mathrm{SH}\right)$, trimethylamine (TMA) and hydrogen sulfodoride $\left(\mathrm{H}_{2} \mathrm{~S}\right)$. Full points indicate that the highest odor activity value is produced by TMA, $\mathrm{H}_{2} \mathrm{~S}$ or $\mathrm{CH}_{3} \mathrm{SH}$.

\section{The Fig. 5a, 5b, 5c and 5d give the log (OAV) profiles of the leading odorous} compounds and the $\log (\mathrm{OC})$ measured during the various storage processes. Methanethiol always produced the highest odor activity value from gas samples likely because of the low redox potential created by the storage conditions. Slight discrepancies were found between odor concentration and the highest odor activity value when storing fresh PSS and fresh PSS mixed with BA, as high concentrations of mercaptan were produced (Fig. 5a and 5b). In contrast, the 15 and 30 days composts were responsible for lower mercaptan 
602

603

604

605

606

607

608

609

610

611

612

613

614

615

616

617

618

619

620

621

622

623

concentrations and, even with similar trends, a larger discrepancy between odor

concentration and the highest odor activity values. A more accurate identification of the mercaptans would likely improve this correlation.

\section{Fig. 4}

Emissions profiles of odor concentration (OC) and odor activity values (OAV) for the leading odorous compounds, namely methanethiol $\left(\mathrm{CH}_{3} \mathrm{SH}\right)$, trimethylamine (TMA) and hydrogen sulfide $\left(\mathrm{H}_{2} \mathrm{~S}\right)$, emitted during the storage of fresh pig slaughterhouse sludge (PSS), fresh pig slaughterhouse sludge mixed with bulking agent (PSS+BA) and composted pig slaughterhouse sludge after 15 and 30 days of treatment. Full points indicate that the highest odor activity value is produced by TMA, or $\mathrm{H}_{2} \mathrm{~S}$ or $\mathrm{CH}_{3} \mathrm{SH}$.

\section{Conclusion}

The objective of this research was to correlate the chemical characterization of odor emissions with their odor concentration as measured by olfactometry. The emissions analysed in this project were obtained from the composting and storage of pig slaughterhouse sludge. Two correlations were investigated to relate odor concentration

(OC) with the chemical composition of the gas sample. The first, based on principles of olfactometric analysis, assumed that the highest odor activity value of the gas sample $\left(\mathrm{OAV}_{\mathrm{MAX}}\right)$ corresponded to $\mathrm{OC}$, whereas the second used the sum of the odor activity values for each compound in the sample. 
The value of the highest OAV quantitatively gave a better prediction of the odor activity value, as compared to that of the sum of OAVs. However, OAV $V_{\text {MAX }}$ and $\mathrm{OAV}_{\text {SUM }}$ were two close mathematical functions, as both showed a good linear regression with the odor concentration, indicating that both could predict the odor concentration. A qualitative comparison of $\mathrm{OAV}_{\mathrm{MAX}}$ and $\mathrm{OAV}_{\mathrm{SUM}}$ indicated that $\mathrm{OAV}_{\mathrm{MAX}}$ was a more relevant predictor than $\mathrm{OAV}_{\text {SUM }}$ which tended to overestimate the odor concentration.

Three main odorous compounds were found to produce $O A V_{\text {MAX }}$ in the 66 samples analyzed: trimethylamine, hydrogen sulfide and mercaptans. Accordingly, the odor determination by dilution-to-threshold method was mostly characterized by the compound with the highest odor activity value $\left(\mathrm{OAV}_{\mathrm{MAX}}\right)$. Nevertheless, $O A V_{\text {MAX }}$ did not always fall within the $95 \%$ confidence interval established for the odor concentration, because: mercaptans were mostly represented by methanethiol; the quantification method for hydrogen sulfide and mercaptans was not sufficiently accurate; no synergy was presumed between compounds forming the gas samples, and; odor threshold determination was drawn on geometric means to describe the central tendency of the threshold value. Regardless of the mathematical function used for correlation, odor activity values were a poor predictor for low odor concentrations, namely under 1000 OU.m ${ }^{-3}$, likely because very low odor detection threshold are often below the GC-MS detection limits leading to an

underestimation of the odor activity value.

\section{Acknowledgements}

The authors wish to acknowledge La Région Bretagne and l’Université Européenne de Bretagne for their financial contributions and that of the Natural Science and Engineering 
647

648

649

650

651

652

653

654

655

656

657

658

659

660

661

662

663

664

665

666

667

668

Research Council of Canada. We would also like to thank the panelists for their investment and their cooperation during the odor measurements.

\section{References}

[1] M. Aatamila, P.K. Verkasalo, M.J. Korhonen, A.L. Suominen, M.R. Hirvonen, M.K. Viluksela, A. Nevalainen, Odor annoyance and physical symptoms among residents living near waste treatment centres, Environmental Research 111 (1) (2010) 164-170.

[2] C.J. Tsai, M.L. Chen, A.D. Ye, M.S. Chou, S.H. Shen, I.F. Mao, The relationship of odor concentration and the critical components emitted from food waste composting plants, Atmospheric Environment 42 (35) (2008) 8246-8251.

[3] C. Coker, Managing odors in organics recycling, BioCycle 53 (4) (2012) 25-28.

[4] M. Schlegelmilch, J. Streese, W. Biedermann, T. Herold, R. Stegmann, Odor control at biowaste composting facilities, Waste Management 25(9) (2005) 917-927.

[5] K.R. Murphy, G. Parcsi, R.M. Stuetz, Non-methane volatile organic compounds predict odor emitted from five tunnel ventilated broiler sheds, Chemosphere 95 (2014) $423-432$. 
669

670

671

672

673

674

675

676

677

678

679

680

681

682

683

684

685

686

687

688

689

690

691

[6] D.B. Parker, J.A. Koziel, L. Cai, L.D. Jacobson, N. Akdeniz, S.D. Bereznicki, T.T. Lim, E.A. Caraway, S. Zhang, S.J. Hoff, A.J. Heber, K.Y. Heathcote, B.P. Hetchler, Odor and odorous chemical emissions from animal buildings: Part 6. Odor activity value, Transactions of the ASABE. 55(6) (2012) 2357-2368.

[7] J.E. Friedrich and T. E. Acree, Gas chromatograph olfactometry (GC/O) of dairy products, International Dairy Journal 8(3) (1998) 235-241.

[8] S.L. Trabue, J.C. Anhalt, J.A. Zahn, Bias of Tedlar bags in the measurement of agricultural odorants, Journal of Environmental Quality 35(5) (2006) 1668-1677.

[9] K.H. Kim and S.Y. Park, A comparative analysis of malodor samples between direct (olfactometry) and indirect (instrumental) methods, Atmospheric Environment 42(20) (2008) 5061-5070.

[10] D.B. Parker, Z.L. Perschbacher-Buser, N. A. Cole, J. A. Koziel, Recovery of agricultural odors and odorous compounds from polyvinyl fluoride film bags, Sensors 10(9) (2010) 8536-8552.

[11] E, Gallego. F.J. Roca, J.F. Perales, G. Sánchez, P. Esplugas, Characterization and determination of the odorous charge in the indoor air of a waste treatment facility through the evaluation of volatile organic compounds (VOCs) using TD-GC-MS, Waste Management 32(12) (2012) 2469-2481. 
692

693

694

695

696

697

698

699

700

701

702

703

704

705

706

707

708

709

710

711

712

[12] EN 13725, Air Quality - Determination of odor concentration by dynamic olfactometry, AFNOR, 2003.

[13] R. Noble, P.J. Hobbs, A. Dobrovin-Pennington, T.H. Misselbrook, A. Mead, Olfactory response to mushroom composting emissions as a function of chemical concentration, Journal of Environmental Quality 30(3) (2001) 760-767.

[14] D. Hanajima, K. Kuroda, K. Morishita, J. Fujita, K. Maeda, K. Morioka, Key odor components responsible for the impact on olfactory sense during swine feces composting, Bioresource Technology 101(7) (2010) 2306-2310.

[15] I.F. Mao, C.J. Tsai, S.H. Shen, T.F. Lin, W.K. Chen, M.L. Chen, Critical components of odors in evaluating the performance of food waste composting plants. Science of the Total Environment 370(2-3) (2006) 323-329.

[16] N. Defoer, I. De Bo, H. Van Langenhove, J. Dewulf, T. Van Elst, Gas chromatography-mass spectrometry as a tool for estimating odor concentrations of biofilter effluents at aerobic composting and rendering plants, Journal of Chromatography 970(1-2) (2002) 259-273. 
713

714

715

716

717

718

719

720

721

725

726

727

728

729

730

731

732

733

734

735

[17] A.K. Gralapp, W.J. Powers, D.S. Bundy, D.S., 2001. Comparison of olfactometry, gas chromatography, and electronic nose technology for measurement of indoor air from swine facilities. Swine Research Report, 2000. Paper 28 (2001).

[18] M.J. Hansen, A.P.S. Adamsen, P. Pedersen, A. Feilberg, A., 2012. Prediction of odor from pig production based on chemical odorants. Journal of Environmental Quality 41(2012) 436-443.

[19] V. Blanes-Vidal, M.N. Hansen, A.P.S. Adamsen, A. Feilberg, S.O. Petersen, B.B. Jensen. Characterization of odor released during handling of swine slurry: Part I. Relationship between odorants and perceived odor concentrations. Atmospheric Environment 43(2009) 2997-3005.

[20] P.J. Hobbs, T.H. Misselbrook, T.R. Cumby. Production and emission of odors and gases from ageing pig waste. Journal of Agricultural Engineering Research 72 (1999) $291-298$.

[21]W. Groves and E. Zellers, Investigation of organic vapor losses to condensed water vapor in Tedlar bags used for exhaled-breath sampling, American Industrial Hygiene Association Journal 57 (1996) 257-263.

[22] J.A. Koziel, J.P. Spinhirne, J.D. Lloyd, D.B. Parker, D.W. Wright, F.W. Kuhrt. Evaluation of sample recovery of malodorous livestock gases from air sampling bags, 
738

739

740

741

742

743

744

745

746

747

748

749

750

751

752

753

754

755

756

757

solid-phase microextraction fi bers, Tenax TA sorbent tubes, and sampling canisters. Journal of the Air and Waste Management Association, 55 (2005) 1147-1157.

[23] M. Sulyok, M., C. Haberhauer-Troyer, E. Rosenberg, M. Grasserbauer. Investigation of the storage stability of selected volatile sulfur compounds in different sampling containers. Journal of Chromatography A, 917 (2001) 367-374.

[24] S.L. Trabue, J.C. Anhalt, J.A. Zahn. 2006. Bias of Tedlar bags in the measurement of agricultural odorants. Journal of Environmental Quality 35 (2006) 1668-1677.

[25] J.M. Guillot and S. Beghi. Permeability to water vapour and hydrogen sulphide of some sampling bags recommended by EN 13725. Chemical Engineering Transaction, 15 (2008) 79-85.

[26] M.J. Hansen, A.P.S. Adamsen, A. Feilberg, K.E.N. Jonassen. Stability of odorants from pig production in sampling bags for olfactometry. Journal of Environmental Quality, 40 (2011) 1096-1102.

[27] P. Mochalski, B. Wzorek, I. Sliwka, A. Amann. Suitability of different polymer bags for storage of volatile sulphur compounds relevant to breath analysis. Journal of Chromatography B, 877 (2009) 189-196. 
758

759

760

761

762

763

764

765

766

767

768

769

770

771

772

773

774

775

776

777

778

779

780

[28] A.Ph. Van Harreveld. Odor concentration decay and stability in gas sampling bags. Journal of the Air and Waste Management Association, 53 (2003) 51-60.

[29] W. Wardencki. Sulfur compounds: gas chromatography. I.D. Wilson (Ed.), Encyclopedia of separation science, Academic Press, Oxford (2000), 4285-4301.

[30] M.J. Hansen, A. Feilberg, A.P.S. Adamsen.. Stability of volatile reduced sulphur compounds in the dilution system of an olfactometer. Chemical Engineering Transaction 23 (2010) 67-72.

[31] M.J. Hansen, A.P.S. Adamsen, A. Feilberg. Recovery of Odorants from an Olfactometer Measured by Proton-Transfer-Reaction Mass Spectrometry. Sensors 13(2013) 7860-7871.

[32] NF T90-015-1, Water quality-Determination of ammonium-Part 1: Titrimetric method after steam distillation, 2000.

[33] A. Ribes, G. Carrera, E. Gallego, X. Roca, M.J. Berenguer, X. Guardino, Development and validation of a method for air-quality and nuisance odors monitoring of volatile organic compounds using multi-sorbent adsorption and gas chromatography/mass spectrometry thermal desorption system, Journal of Chromatography 1140(1-2) (2007) 44-55. 
[34] V. Blazy, A. de Guardia, J.C. Benoist, M. Daumoin, M. Lemasle, D. Wolbert, S. Barrington, Odorous gaseous emissions as influence of process condition for the forced aeration composting of pig slaughterhouse sludge, Waste Management 34(7) (2014) 1125-1138.

[36] L.J. Van Gemert, Odor Threshold - Compilation of Odor Threshold Values in Air, Water and Other Media, Oliemans Punter \& Partners BV, 2011.

[37] Y. Nagata, Measurement of odor threshold by triangle odor bag method, Bulletin of Japan Environmental Sanitation Center 17 (2003) 77-89.

[38] P.H. Dalton, D.D. Dilks, M.I. Banton, Evaluation of odor and sensory irritation thresholds for methyl isobutyl ketone in humans. American Industrial Hygiene Association Journal 61(2000) 340-350.

[39] K. Korneev, E. Yu, Effect of the combined presence of low concentrations of phenol and acetophenone in the urban atmosphere, Hygiene and Sanitation USSR 30 (7-9) (1965) 336-345.

[40] R. Savenhed, H. Boren, A. Grimvall, Stripping analysis and chromatographic sniffing for the source identification of odorous compounds in driking water, Journal of Chromatography 328 (1985) 219-231. 
803

804

805

806

807

808

809

810

811

812

813

814

815

816

817

818

819

820

821

822

823

824

[41] N.B. Imasheva, The substantiation of the maximum permissible concentration of acetophenon in the atmospheric air (in Russia), Hygiene and Sanitation 28 (2) (1963) $3-8$.

[42] N.Z. Tkach, Combined effect of acetone and acetophenone in the atmosphere, Hygiene and Sanitation, USSR 30 (7-9) (1965) 179-185.

[43] M.A.M. Smeets, P.J. Bulsing, S. Van Rooden, R. Steinman, J.A. De Ru, N.W.M.

Ogink, C. Van Triel, P.H. Dalton, Odor and irritation thresholds for ammonia: a comparison between static and dynamic olfactometry, Chemical Senses 32 (2007) 1120.

[44] J. Greenman, J. Duffield, P. Spencer, M. Rosenberg, D. Corry, S. Saad, P. Lenton, G. Majerus, S. Nachnani, M. El-Maaytah, Study on the organoleptic intensity scale for measuring malodor, Journal of Dental Research 83 (2004) 81-85.

[45] ADEME, Pollution olfactives, Dunod ed., l'usine nouvelle, Paris, 2005.

[46] H. Ueno, S. Amano, B. Merecka, J. Kosmider, Difference in the odor concentration measured by the trianble odor bag method and dynamic olfactometry, Water Science Technology 59 (2009) 1339-1342. 
828

829

830

831

832

[47] M.A. McGinley, C.M. McGinley, Comparison of field olfactometers in a controlled chamber using hydrogen sulphide as the test odorant, Water Science Technology 50 (4) (2004) 75-82.

[48] W.S. Cain, M.L. Dourson, M.J. Kohrman-Vincent, B.C. Allen, Human chemosensory perception of methyl isothiocyanate: chemesthesis and odor, Regulatory Toxicology and Pharmacology 58 (2010) 173-180.

[49] D.S. Yang, R.L. Shewfelt, K.S. Lee, S.J. Kays, Comparison of odor-active compounds from six distincly different rice flavor types, Journal of Agricultural and Food Chemistry 56 (2008) 2780-2787.

[50] G.Z. Nagy, The odor impact model, Journal of the Air \& Waste Management Association, 41 (1991) 1360-1362.

[51] J.A. Don., Odor measurement and control, Paper presented at odor control in industry, London, March 181986.

[52] Y. Hoshika, T. Imamura, G. Muto, L.J. Van Gemert, J.A. Don, J.I. Walpot, International comparison of odor threshold values of several odorants in Japan and in the Netherlands, Environmental Resources 61 (1993) 78-83. 
847

848

849

850

851

852

853

854

855

856

857

858

859

860

861

862

863

864

865

866

867

868

869

[53] J.E. Cometto-Muniz, M.H. Abraham, Olfactory detedtability of homologous nalkylbenzenes as reflected by concentration-detection functions in humans, Neuroscience 161 (2009) 236-248.

[54] R.H. Gundlach, G. Kenway, A method for the determination of olfactory thresholds in humans, Journal of Experimental Psychology 24(2) (1939) 192-201.

[55] S.H. Katz and E.J. Talbert, Intensities of odors an irritating effects of warning agents for inflammable and poisonous gases. U.S. Bureau of Mines, Technical report $n^{\circ} 480$, 1930.

[56] P.M. Wise, T. Miyazawa, M. Gallagher, G. Petri, Human odor detection of homologous carboxylic acids and their binary mixtures, Chemical Senses, 32 (2007), $475-482$.

[57] T. Miyazawa, M. Gallagher, G. Petri, P.M. Wise, Odor detection of mixtures of homologous carboxylic acids and coffee aroma compounds by humans, Journal of Agricultural and Food Chemistry (2009) 9895-9901.

[58] J.E. Cometto-Muniz, M.H. Abraham, Structure-activity relationships on the odor detectability of homologous carboxylic acids by humans, Experimental Brain Research 207 (2010) 75-84. 
870

871

872

873

874

875

876

877

878

879

880

881

882

883

884

885

886

887

888

889

890

891

892

[59] G. Parcsi, E.C. Sivret, X. Wang, R.M. Stuetz. Fate of sulfur odorants in odor collection. AWA Odor Specialty Conference 24-25 August, Sydney, 2010.

[60] J.A. Zahn, A.A. DiSpirito, Y.S. Do, B.E. Brooks, E.E. Cooper, J.L. Hatfield, Correlation of human olfactory responses to airborne concentrations of malodorous volatile organic compounds emitted from swine effluent, Journal of Environmental Quality 30(2) (2001) 624-634.

[61] VDI 3882 Part 1, 1992. Olfactometry Determination of Odor Intensity, Technische Regel. Von Braun, J., 1927. Geruch und molekulare asymetrie, IV. Mitteilung: Die drei 1.3-Dimethylcyclohexanone-5 und die vier 1.3-Dimethyl-cyclohexanole-5. Berichte der deutschen chemischen Gesellschatt (A and B Series),60(11), 1927, 2438-2446.

[62] ASTM standard E544-10, Standard practices for referencing suprathreshold odor intensity, ASTM international (2010), West Conshohocken, PA.

[63] K.H. Kim, The ayeraging effect of odorant mixing as determined by air dilution sensory tests: A case study on reduced sulfur compounds, Sensors 11 (2011) 14051417.

[64] P. Zhao, J.M. Liu, S.C. Tang, The interaction of mixing odorants with similar chemical properties: A case study on ketone compounds (Conference paper), Advanced Materials Research, International Forum on Materials Analysis and Testing Technology 850-851 (2013) 32-37. 
893

894

895

[65] V. Blazy, A. de Guardia, J.C. Benoist, M. Daumoin, M. Lemasle, D. Wolbert, S. Barrington, Process Conditions Influence on Pig Slaughter House Compost Quality Under Forced Aeration, Waste and Biomass Valorization 5(3) (2014) 451-468. 


\section{Table 1}

Mixtures compositions and experimental conditions

\begin{tabular}{|c|c|c|c|c|c|c|c|}
\hline & \multicolumn{4}{|c|}{ Storage experiments } & \multicolumn{3}{|c|}{$\begin{array}{l}\text { Composting } \\
\text { experiments }\end{array}$} \\
\hline Material composition & $\begin{array}{c}\text { Fresh } \\
\text { PSS }\end{array}$ & $\begin{array}{c}\text { Fresh } \\
\text { PSS+BA }\end{array}$ & $\begin{array}{c}\text { PSS } \\
\text { compost } \\
\text { at } 15 \text { days } \\
\end{array}$ & $\begin{array}{c}\text { PSS } \\
\text { compost at } \\
\mathbf{3 0} \text { days } \\
\end{array}$ & & esh PSS & \\
\hline PSS or compost fresh mass $(\mathrm{kg})$ & 24.44 & 11.57 & 10.75 & 11.07 & 59.76 & 58.52 & 58.75 \\
\hline Bulking agent fresh mass $(\mathrm{kg})$ & - & 9.63 & - & - & 43.75 & 42.84 & 32.25 \\
\hline Water added (kg) & - & - & - & - & & 6.83 & - \\
\hline Fresh mass ratio (BA/PSS) & - & 0.83 & - & - & 0.73 & 0.73 & 0.55 \\
\hline Mixture moisture (\%) & 76.3 & 51.9 & 46.1 & 35.6 & 61.2 & 63.7 & 63.6 \\
\hline \multicolumn{8}{|c|}{ Experimental conditions } \\
\hline Mean aeration rate $\left(\mathrm{L} \cdot \mathrm{h}^{-1}\right)$ & 42.2 & 38.4 & 42.5 & 41.7 & 553 & 554 & 556 \\
\hline number of turning material & - & - & - & & 3 & 3 & 3 \\
\hline end of the experimentation (days) & 29.6 & 13.9 & 15.7 & 15.9 & 35.5 & 35.5 & 35.5 \\
\hline
\end{tabular}

PSS: pig slaughterhouse sludge; BA: bulking agent 


\section{Table 2}

Gaseous compounds identified from emissions collected during the composting and the storage of pig slaughterhouse sludge

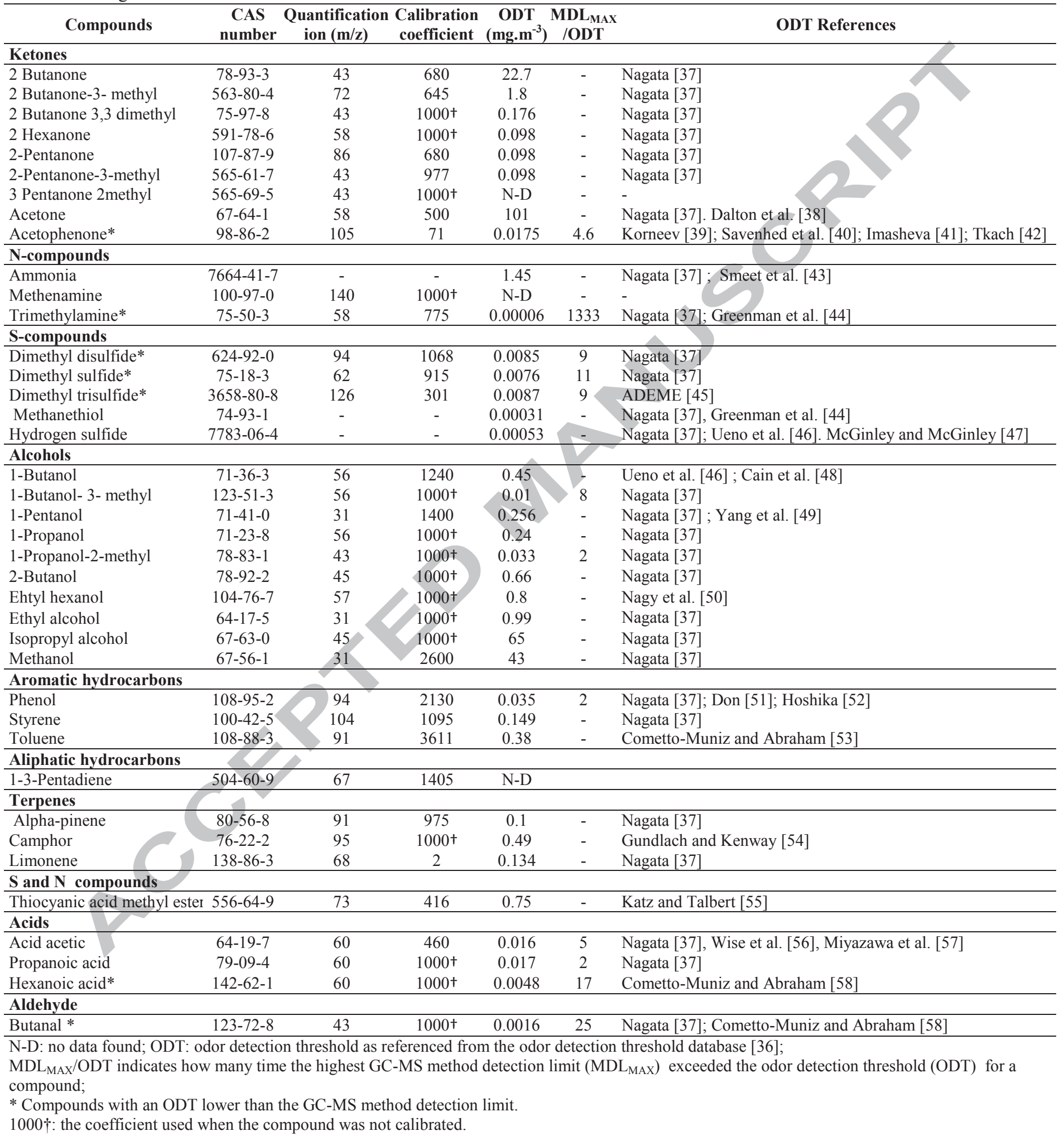




\section{Table 3}

Comparison of the absolute relative deviation of $\mathrm{OAV}_{\mathrm{MAX}}$ and $\mathrm{OAV}_{\mathrm{SUM}}$ with respect to the $95 \%$ confidence interval for odor concentration measurement

\begin{tabular}{lccc}
\hline & Number of & \multicolumn{2}{c}{ Mean Abs RD (\%) } \\
\cline { 2 - 3 } & mixture & OAV $_{\text {MAX }}$ & OAV $_{\text {SUM }}$ \\
\hline OAV $_{\text {MAX }}$ and OAV & $16(24 \%)$ & 68 & 103 \\
OAV $_{\text {MAX }}$ is outside the confident limits of OC measure & $25(38 \%)$ & 53 & - \\
OAV $_{\text {SUM }}$ is outside the confident limits of OC measure & $31(47 \%)$ & - & 73 \\
\hline
\end{tabular}

$\mathrm{OC}$, odor concentration of a gaseous emission measured by olfactometry and corresponding to the number of dilution required for its odor to be undetected; $O A V_{M A X}:$ maximal odor activity value within a mixture; OAV $V_{S U M}$ : sum of every odor activity values of a mixture; Abs RD: absolute relative deviation value 


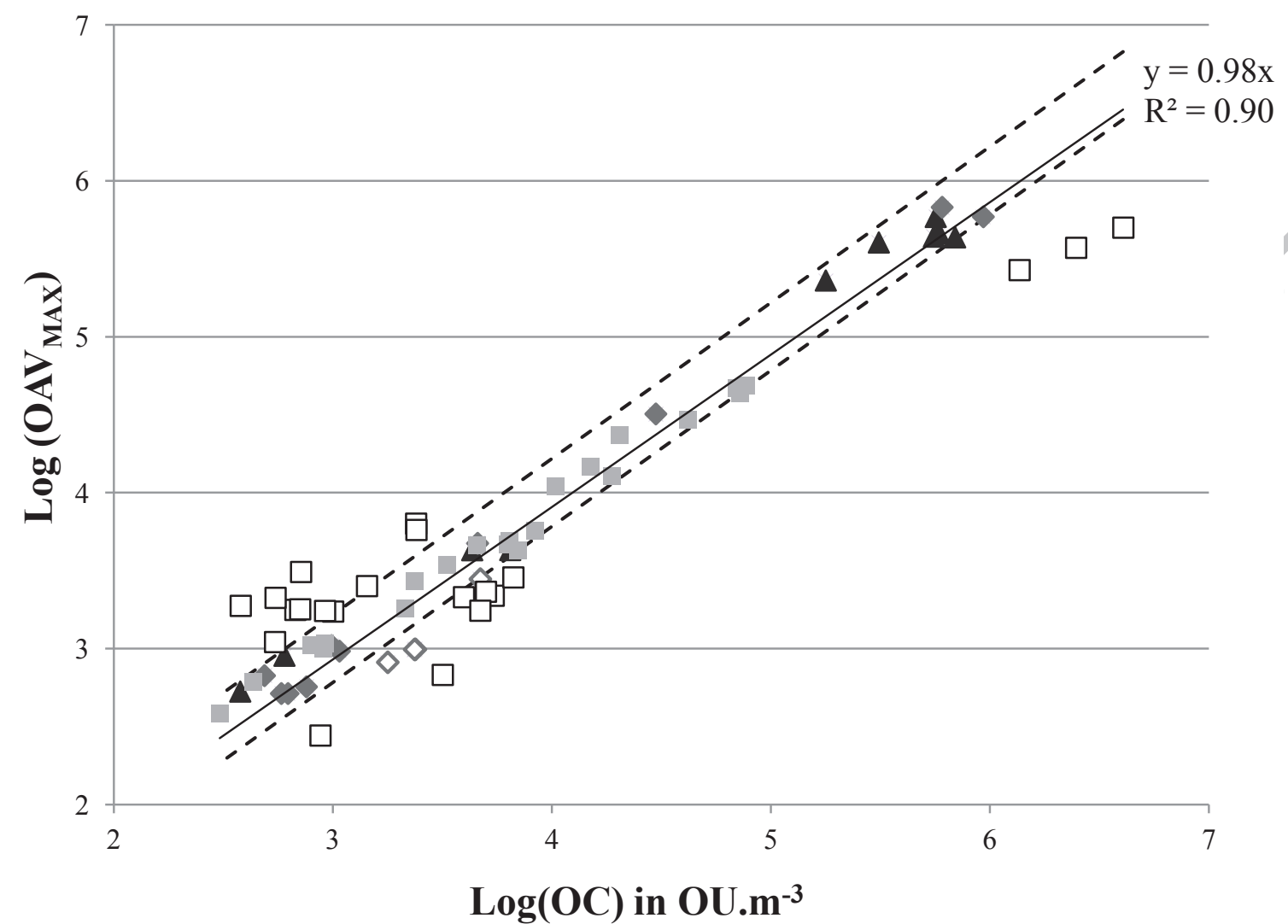

Fitted line between Log (OC) and $\log \left(\mathrm{OAV}_{\mathrm{MAX}}\right)$

Fig.1 Predicted Log $\left(O A V_{M A X}\right)$ as function of measured $\log (O C)\left(O A V_{\text {MAX }}\right.$ is the odor activity value (OAV) of the most odorous compound, namely the compound with the highest concentration/odor detection threshold value; the odor concentration (OC) was measured by olfatometry. Hollow points stand outside the confidence interval of the odor concentration). 


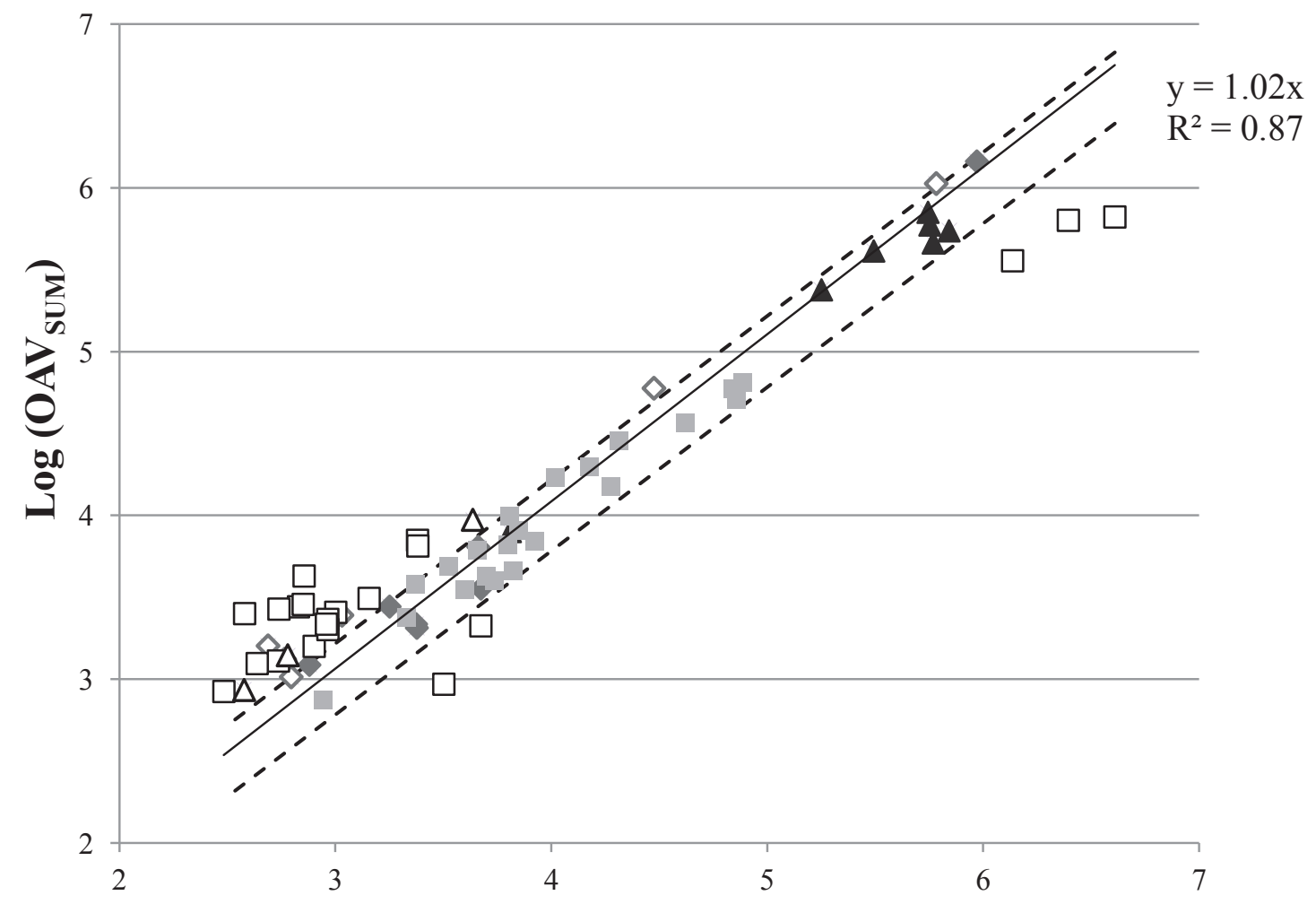

$\log (\mathrm{OC})$ in $\mathrm{OU} \cdot \mathrm{m}^{-3}$

— Fitted line between $\log (\mathrm{OC})$ and $\log \left(\mathrm{OAV}_{\mathrm{SUM}}\right)$

$\Delta$ Sum of the odor activity value of a sample when $\mathrm{H}_{2} \mathrm{~S}$ is the leading odorous compound as function of the odor concentration

Sum of the odor activity value of a sample when TMA is the leading odorous compound as function of the odor concentration

Sum of the odor activity value of a sample when $\mathrm{CH}_{3} \mathrm{SH}$ is the leading odorous compound as function of the odor concentration

Fig.2. Predicted $\log \left(\mathrm{OAV}_{\mathrm{SUM}}\right)$ as function of measured $\mathrm{OC}\left(\mathrm{OAV}_{\mathrm{SUM}}\right.$ was obtained by summing the OAV of every odorous compound found in the gas sample; the odor concentration (OC) was measured by olfatometry. Hollow points are out of the confidence limits of the OC measure). 


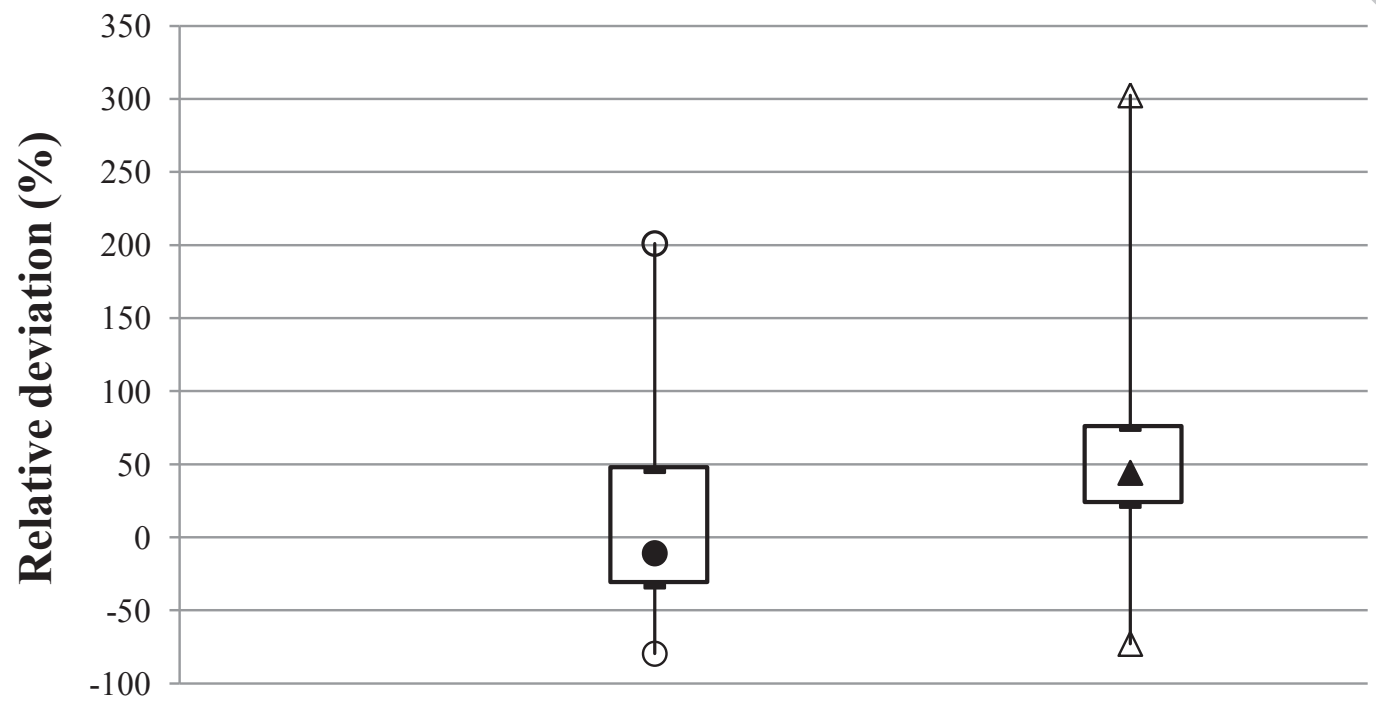

- Box plot of the Relative Deviation between the closest odor concentration interval boundaries and the maximal odor activity value within a sample outside the odor concentration confident interval

$\Delta$ Box plot of the Relative Deviation between the closest odor concentration interval boundaries and the sum of every odor activity values of a sample outside the odour concentration confident interval

Fig.3. Box plot of the Relative Deviation between the closest odor concentration interval boundaries $\left(\mathrm{OC}_{\mathrm{INT}}\right)$ and the maximal odor activity value within a sample outside the odor concentration confident interval, and; between $\mathrm{OC}_{\mathrm{INT}}$ and the sum of every odor activity values of a sample outside the odor concentration confident interval. 
a

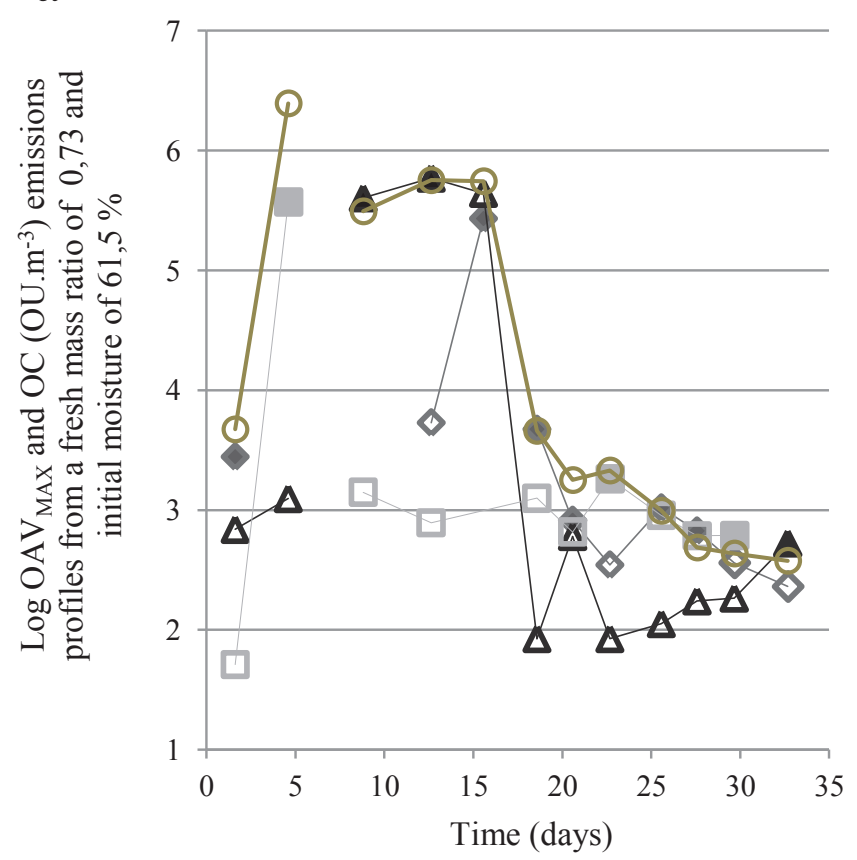

\section{ACCEPTED MANUSCRIPT}
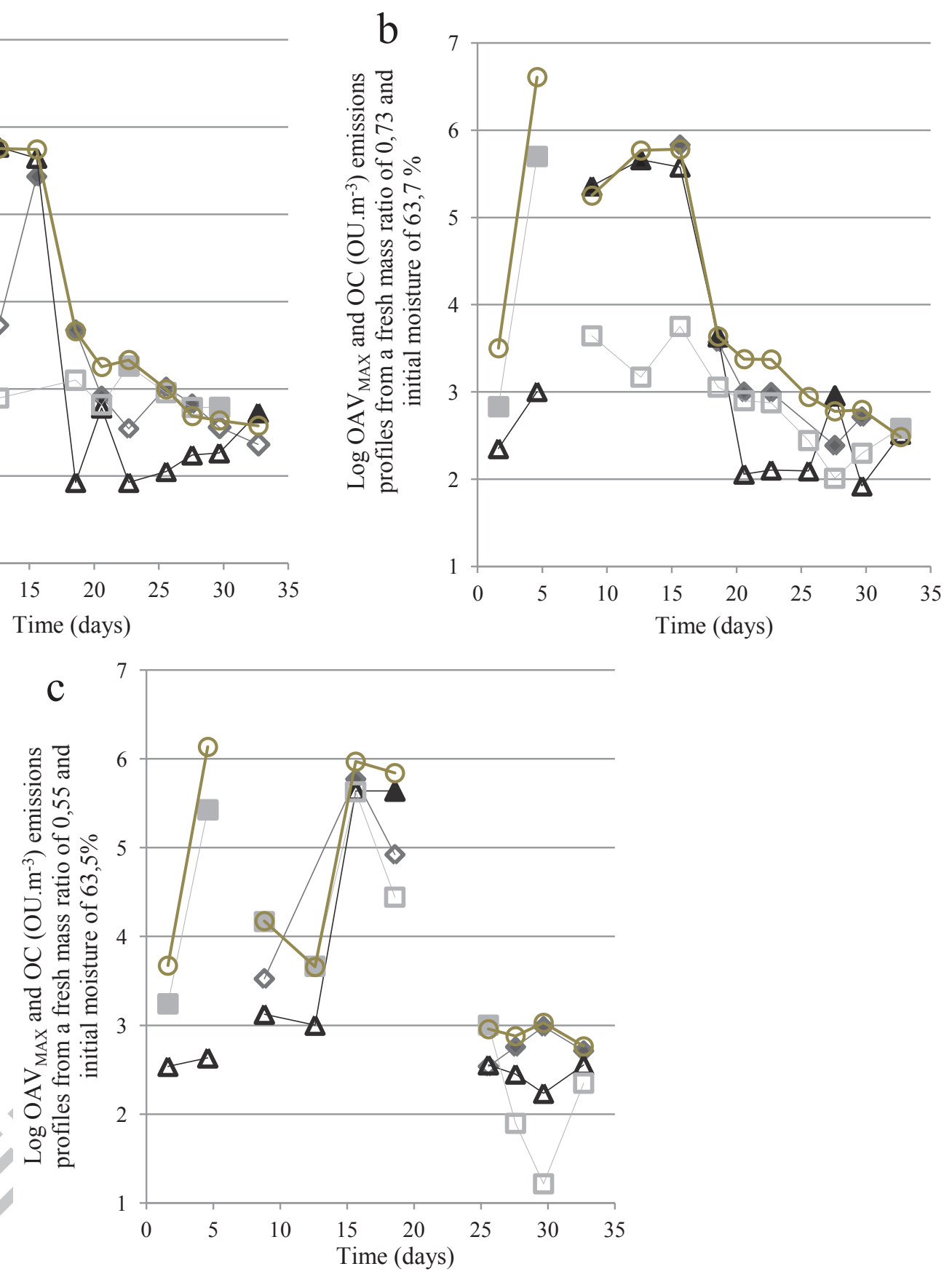

- Odor activity value of TMA during composting

Odor activity value of $\mathrm{CH}_{3} \mathrm{SH}$ during composting

Odor activity value of $\mathrm{H}_{2} \mathrm{~S}$ during composting Olfactory odor concentration (OC)

Fig. $\square$ Composting emissions profiles of odor concentration (OC) and odor activity value (OAV) for the leading odorous compounds, namely methanethiol $\left(\mathrm{CH}_{3} \mathrm{SH}\right)$, trimethylamine (TMA) and hydrogen sulfide $\left(\mathrm{H}_{2} \mathrm{~S}\right)$. Full points indicate that the highest odor activity value is produced by TMA, $\mathrm{H}_{2} \mathrm{~S}$ or $\mathrm{CH}_{3} \mathrm{SH}$. 

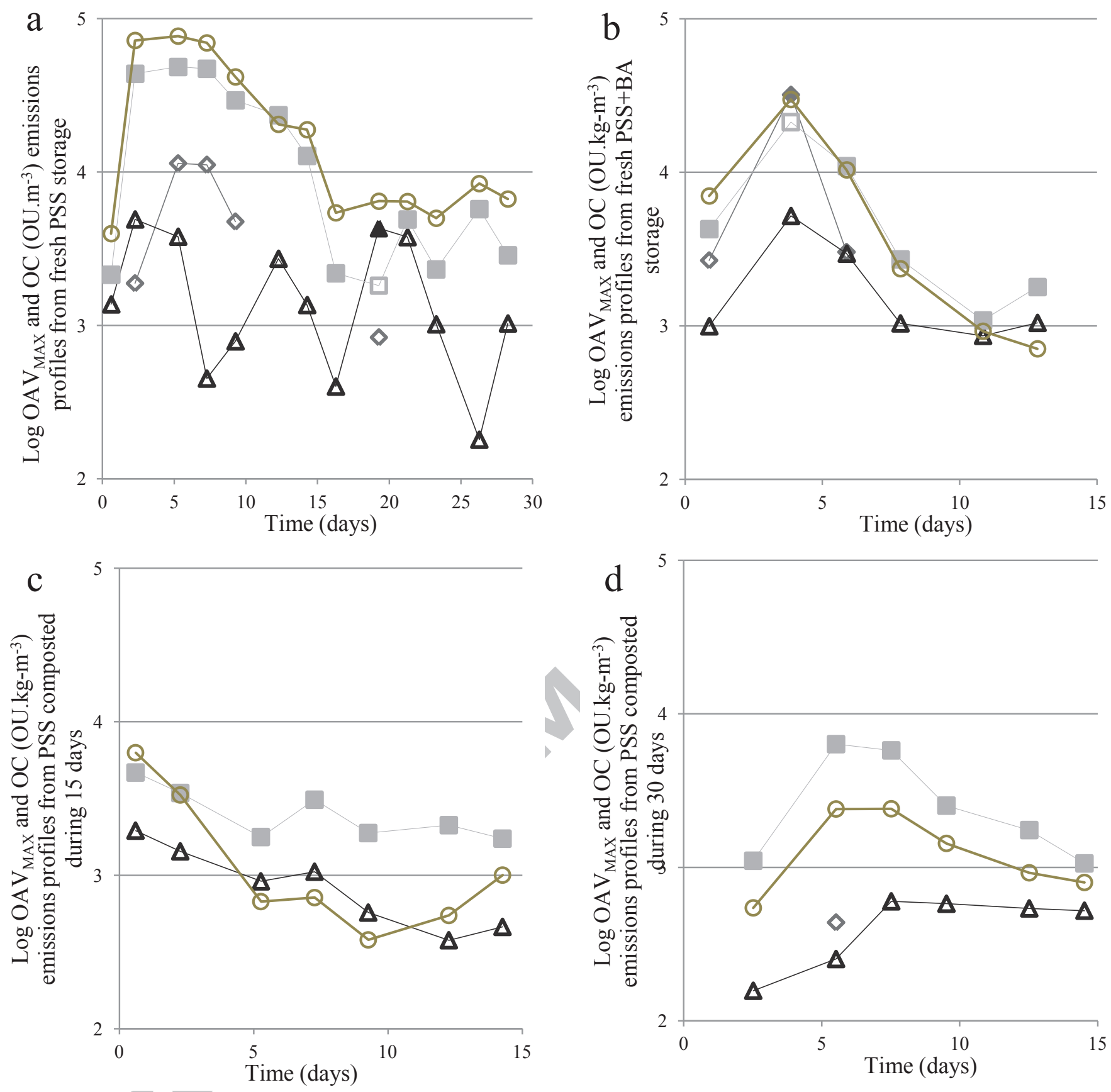

Odor activity value of TMA during storage

$\triangle-$ Odor activity value of $\mathrm{H}_{2} \mathrm{~S}$ during storage

Odor activity value of $\mathrm{CH}_{3} \mathrm{SH}$ during storage

-o- Olfactory odor concentration (OC)

Fig. $\sqsubset$ Emissions profiles of odor concentration (OC) and odor activity values (OAV) for the leading odorous compounds, namely methanethiol $\left(\mathrm{CH}_{3} \mathrm{SH}\right)$, trimethylamine (TMA) and hydrogen sulfide $\left(\mathrm{H}_{2} \mathrm{~S}\right)$, emitted during the storage of fresh pig slaughterhouse sludge (PSS), 
fresh pig slaughterhouse sludge mixed with bulking agent (PSS+BA) and composted pig slaughterhouse sludge after 15 and 30 days of treatment. Full points indicate that the highest odor activity value is produced by TMA, or $\mathrm{H}_{2} \mathrm{~S}$ or $\mathrm{CH}_{3} \mathrm{SH}$. 
$\square$ ig $\square$ ig $\square \square$

PSS composting and storage gas samples were determined by chemical and olfactory analyses

For gas samples, correlations between the chemical composition and its OC was investigated

$\mathrm{OAV}_{\mathrm{MAX}}$ assumed that $\mathrm{OC}$ was equal to the sample's highest $\mathrm{OAV}$ value

$\mathrm{OAV}_{\text {sum }}$ assumed that $\mathrm{OC}$ was equal to the sum of all OAV for sample

The 3 most odorant compound offered a good prediction of the olfactory results. 